Article

\title{
Model of Daytime Oxygen Emissions in the Mesopause Region and Above: A Review and New Results
}

\author{
Valentine Yankovsky *(D) and Ekaterina Vorobeva \\ Atmospheric Physics Department, Saint Petersburg State University, 7/9 Universitetskaya nab., \\ 199034 Saint Petersburg, Russia \\ * Correspondence: vyankovsky@gmail.com
}

Received: 25 November 2019; Accepted: 17 January 2020; Published: 19 January 2020

check for updates

\begin{abstract}
Atmospheric emissions of atomic and molecular oxygen have been observed since the middle of 19th century. In the last decades, it has been shown that emissions of excited oxygen atom $\mathrm{O}\left({ }^{1} \mathrm{D}\right)$ and molecular oxygen in electronically-vibrationally excited states $\mathrm{O}_{2}\left(\mathrm{~b}^{1} \Sigma^{+} \mathrm{g}, \mathrm{v}\right)$ and $\mathrm{O}_{2}\left(\mathrm{a}^{1} \Delta_{\mathrm{g}}\right.$, v) are related by a unified photochemical mechanism in the mesosphere and lower thermosphere (MLT). The current paper consists of two parts: a review of studies related to the development of the model of ozone and molecular oxygen photodissociation in the daytime MLT and new results. In particular, the paper includes a detailed description of formation mechanism for excited oxygen components in the daytime MLT and presents comparison of widely used photochemical models. The paper also demonstrates new results such as new suggestions about possible products for collisional reactions of electronically-vibrationally excited oxygen molecules with atomic oxygen and new estimations of $\mathrm{O}_{2}\left(\mathrm{~b}^{1} \Sigma^{+} \mathrm{g}, \mathrm{v}=0-10\right)$ radiative lifetimes which are necessary for solving inverse problems in the lower thermosphere. Moreover, special attention is given to the "Barth's mechanism" in order to demonstrate that for different sets of fitting coefficients its contribution to $\mathrm{O}_{2}\left(\mathrm{~b}^{1} \Sigma^{+} \mathrm{g}, \mathrm{v}\right)$ and $\mathrm{O}_{2}\left(\mathrm{a}^{1} \Delta_{\mathrm{g}}, \mathrm{v}\right)$ population is neglectable in daytime conditions. In addition to the review and new results, possible applications of the daytime oxygen emissions are presented, e.g., the altitude profiles $\mathrm{O}\left({ }^{3} \mathrm{P}\right), \mathrm{O}_{3}$ and $\mathrm{CO}_{2}$ can be retrieved by solving inverse photochemical problems when emissions from electronically vibrationally excited states of $\mathrm{O}_{2}$ molecule are used as proxies.
\end{abstract}

Keywords: oxygen dayglow chemistry; $\mathrm{O}_{2}$ photo-chemical modelling; electronic-vibrational state hierarchy

\section{Introduction}

The dayglow and nightglow are dominated by two powerful bands of molecular oxygen, having the names: $\mathrm{O}_{2}$ IR atmospheric (0-0) band with a center at $1.27 \mu \mathrm{m}$ and $\mathrm{O}_{2}$ atmospheric (0-0) band with a center at $0.762 \mu \mathrm{m}$. Sources of these emissions are optical transitions between electronically-vibrational excited levels of $\mathrm{O}_{2}$ molecule: $\mathrm{O}_{2}\left(\mathrm{a}^{1} \Delta_{\mathrm{g}}, \mathrm{v}^{\prime}=0 \rightarrow \mathrm{X}^{3} \Sigma_{\mathrm{g}}{ }^{-}, \mathrm{v}^{\prime \prime}=0\right)$ and $\mathrm{O}_{2}\left(\mathrm{~b}^{1} \Sigma_{\mathrm{g}}{ }^{+}, \mathrm{v}^{\prime}=0 \rightarrow \mathrm{X}^{3} \Sigma_{\mathrm{g}}{ }^{-}, \mathrm{v}^{\prime \prime}=0\right)$, respectively. In the last decades, it has been shown that emissions of excited oxygen atom $\mathrm{O}\left({ }^{1} \mathrm{D}\right)$ and molecular oxygen in electronically-vibrationally excited states $\mathrm{O}_{2}\left(\mathrm{~b}^{1} \Sigma^{+}{ }_{\mathrm{g}}, \mathrm{v}\right)$ and $\mathrm{O}_{2}\left(\mathrm{a}^{1} \Delta_{\mathrm{g}}, \mathrm{v}\right)$ are related by a unified photochemical mechanism in the daytime mesosphere and lower thermosphere (MLT). A recent model which describes this mechanism is the YM2011 model [1,2]. However, before proceeding to the discussion and description of the model and its updates, we would like to present a brief overview of previous studies.

Measurements of volume emission rate (VER) of the atmospheric bands started in 1970s, however, for further interpretation and solving inverse problem it was necessary to design a photochemical 
model which describes formation of excited oxygen components in the atmosphere (Section 2). First attempts to create such a model are presented in [3-14] etc. These studies led to the creation of two widely known models. In 1986, based on results of multi-rocket ETON (Energy Transfer in the Oxygen Nightglow) experiment, a full-featured model of oxygen emissions at nighttime conditions was designed [15-17]. Note that this model is still used for interpretation of rocket experiments [18-20]. In 1993, a model considering emissions of $\mathrm{O}_{2}$ atmospheric bands (with centers at $1.27 \mu \mathrm{m}$ and $0.762 \mu \mathrm{m}$ ) at daytime conditions was presented by [21] (henceforth we use abbreviation MSZ). The model was a basis for an algorithm of ozone altitude profile retrieval in the stratosphere-mesosphere region as well as for such satellite experiments as UARS-HRDI, SCIAMACHY, ODIN-OSIRIS, TIMED-SABER, etc.

However, for more than 25 years old history of using, claims to the completeness of these models have accumulated. Until now, questions remain on the mathematical description of the night glow model, where the main source of uncertainty is the altitude profile of atomic oxygen in nighttime conditions. We believe that further improvement of the night glow model is associated with accuracy increase of direct measurement of the atomic oxygen profile at night. Regarding the photochemical model MSZ of daytime oxygen emissions, there are five issues:

1. The main problem is related to the design of the MSZ model. The bottom line is that this model is intended only to explain the altitude profiles of the volume emission rates of atmospheric $(0,0)$ band and IR atmospheric $(0,0)$ band. Although, simultaneously with the $\mathrm{O}_{2}\left(a^{1} \Delta_{g}, v=0\right)$ and $\mathrm{O}_{2}\left(\mathrm{~b}^{1} \Sigma^{+}{ }_{\mathrm{g}}, \mathrm{v}=0\right)$ levels, the electronic-vibrational levels of oxygen molecules with $\mathrm{v} \geq 1$ are populated. Emission transitions from the $\mathrm{O}_{2}\left(\mathrm{a}^{1} \Delta_{\mathrm{g}}, \mathrm{v} \geq 0\right)$ and $\mathrm{O}_{2}\left(\mathrm{~b}^{1} \Sigma^{+} \mathrm{g}, \mathrm{v} \geq 0\right)$ are observed in the atmospheric glow and clearly correlate with each other [12,22-24]. Note that emission bands of an oxygen molecule with much higher levels of vibrational excitation $\mathrm{O}_{2}\left(\mathrm{~b}^{1} \Sigma^{+} \mathrm{g}, \mathrm{v}^{\prime}=0-15\right)$ are also observed in the atmospheric glow [25].

2. The next problem arises from the first. Measured VERs and spectral features of the $\mathrm{O}_{2}$ atmospheric (Atm) (0-0) band are widely used for solving applied tasks such as estimating altitude profiles of kinetic temperature, pressure, aerosol content, cloud height etc. In last decades, it has become technically possible to measure VER from electronically-vibrationally excited levels of $\mathrm{O}_{2}$ molecule with sufficient spectral resolution, e.g., in the $\mathrm{O}_{2} \operatorname{Atm}(1-1), \mathrm{O}_{2} \operatorname{Atm}(2-2), \mathrm{O}_{2} \operatorname{Atm}(2-1)$, $\mathrm{O}_{2}$ IR Atm (1-0) bands and others. Airglow in these bands have been used for remote sensing. However, the main feature of the MSZ model is that it does not consider vibrational excitations at all.

3. A significant uncertainty of ozone altitude profiles retrieved from emission in $1.27 \mu \mathrm{m}$ channel has been found using the MSZ model. As shown based on the analysis of nine satellite experiments [26], values of ozone concentration in the mesosphere and lower thermosphere (MLT) retrieved via the MSZ model are $20 \%-70 \%$ higher than the same obtained by other methods.

4. Currently, there is only one rocket experiment (METEORS) which conducted simultaneous measurements of VERs altitude profiles in Atm (0-0) and IR Atm (0-0) bands [27]. However, ozone altitude profiles retrieved from VERs in Atm and IR Atm bands based on experimental data and using the MSZ model didn't match, although, naturally, they should be identical.

5. The most important issue of modern photochemistry is related with a role of $\mathrm{O}_{2}\left(\mathrm{X}^{3} \Sigma_{\mathrm{g}}{ }^{-}, \mathrm{v}=1\right)$ level [28] which perhaps is a key component in a quasi-resonant energy exchange with $\mathrm{H}_{2} \mathrm{O}(010)$ level. Radiance from the $\mathrm{H}_{2} \mathrm{O}(010)$ level forms the $6.3 \mu \mathrm{m}$ band in water vapor. Naturally, energy transfer from the top electronically-vibrationally excited levels of oxygen molecule $\mathrm{O}_{2}\left(\mathrm{a}^{1} \Delta_{\mathrm{g}}, \mathrm{v}\right)$ and $\mathrm{O}_{2}\left(b^{1} \Sigma^{+} g, v\right)$ should be completed by energy transfer between vibrational levels of ground state of oxygen molecule. The aforementioned energy transfer includes several intermediate steps:

(i) $\mathrm{O}_{2}\left(\mathrm{~b}^{1} \Sigma^{+}{ }_{\mathrm{g}}, \mathrm{v} \geq 1\right) \rightarrow \mathrm{O}_{2}\left(\mathrm{~b}^{1} \Sigma^{+} \mathrm{g}, \mathrm{v}=0\right)$;

(ii) $\mathrm{O}_{2}\left(\mathrm{~b}^{1} \Sigma^{+} \mathrm{g}, \mathrm{v}=0\right) \rightarrow \mathrm{O}_{2}\left(\mathrm{a}^{1} \Delta_{\mathrm{g}}, \mathrm{v} \leq 3\right)$;

(iii) $\mathrm{O}_{2}\left(\mathrm{a}^{1} \Delta_{\mathrm{g}}, \mathrm{v} \geq 1\right) \rightarrow \mathrm{O}_{2}\left(\mathrm{a}^{1} \Delta_{\mathrm{g}}, \mathrm{v}=0\right)$; 


$$
\mathrm{O}_{2}\left(\mathrm{a}^{1} \Delta_{\mathrm{g}}, \mathrm{v}=0\right) \rightarrow \mathrm{O}_{2}\left(\mathrm{X}^{3} \Sigma_{\mathrm{g}}{ }^{-}, \mathrm{v} \leq 5\right)
$$

(v) $\mathrm{O}_{2}\left(\mathrm{X}^{3} \Sigma_{\mathrm{g}}{ }^{-}, \mathrm{v}\right)+\mathrm{N}_{2}\left(\mathrm{X}^{1} \Sigma_{\mathrm{g}}{ }^{+}, \mathrm{v}^{\prime}=0\right) \rightarrow \mathrm{O}_{2}\left(\mathrm{X}^{3} \Sigma_{\mathrm{g}}{ }^{-}, \mathrm{v}-2\right)+\mathrm{N}_{2}\left(\mathrm{X}^{1} \Sigma_{\mathrm{g}}{ }^{+}, \mathrm{v}^{\prime}=1\right)$;

(vi) $\mathrm{O}_{2}\left(\mathrm{X}^{3} \Sigma_{\mathrm{g}}{ }^{-}, \mathrm{v}>1\right) \rightarrow \mathrm{O}_{2}\left(\mathrm{X}^{3} \Sigma_{\mathrm{g}}{ }^{-}, \mathrm{v}=1\right)$;

(vii) $\mathrm{O}_{2}\left(\mathrm{X}^{3} \Sigma_{\mathrm{g}}{ }^{-}, \mathrm{v}=1\right) \leftrightarrow \mathrm{H}_{2} \mathrm{O}(010)$.

The reaction $(\mathrm{v})$ is also quasi-resonant and describes two quantum energy transfer from $\mathrm{O}_{2}\left(\mathrm{X}^{3} \Sigma_{\mathrm{g}}{ }^{-}\right.$, $\mathrm{v}=14-25)$ to $\mathrm{N}_{2}\left(\mathrm{X}^{1} \Sigma_{\mathrm{g}}{ }^{+}, \mathrm{v}=1\right)$ (discovered by Park and Slanger [29]). However, energy transfer to $\mathrm{O}_{2}\left(\mathrm{X}^{3} \Sigma_{\mathrm{g}}{ }^{-}, \mathrm{v} \geq 1\right)$ levels can't be considered in the framework of MSZ model.

It should be noted that vibrational transitions play an important role in the atmospheric energy transfer. E.g., laboratory experiments from the mid 1970s to the present show that energy transfer as a result of $\mathrm{O}_{2}$ and $\mathrm{O}_{3}$ photolysis carried out with participation of electronically-vibrationally excited levels of oxygen molecule. It becomes more clear when considering the mechanism of heating the Earth's atmosphere due to the absorption of UV radiation from the Sun. Absorbed radiation in the range of 120-900 nm leads to $\mathrm{O}_{2}$ and $\mathrm{O}_{3}$ photolysis, and radiation of the Earth's atmosphere is dominating in the near IR range of spectrum. This spectral range corresponds to radiative vibrational transitions of $\mathrm{OH}, \mathrm{H}_{2} \mathrm{O}, \mathrm{CO}_{2}, \mathrm{CO}$ and other atmospheric species.

The model of electronic-vibrational kinetics of $\mathrm{O}_{2}$ and $\mathrm{O}_{3}$ photolysis products in the middle atmosphere which solves all the aforementioned issues and includes the model MSZ as a special case was designed at Atmospheric Physics Department, Saint Petersburg State University [30]. Since 2003, different upgrades of that model have been published [1,2,31-35] etc. The last modified version of the YM2011 will be presented in this study.

The structure of the paper is as follows. Introduction is presented in Section 1. Section 2 describes a procedure of excited oxygen components formation in the daytime MLT. Section 3 presents a detailed description of the YM2011 photochemical model. Possible applications of the YM2011 model are discussed in Section 4. Section 5 includes the conclusions.

\section{Formation of Excited Oxygen Components in the Daytime MLT}

At first, to model the altitude emission profiles of excited oxygen components, we need to understand the mechanisms of their formation and quenching. In the daytime mesosphere and lower thermosphere (MLT), the main sources of excitation for electronic-vibrational levels of oxygen molecule can be divided into (i) photo processes, namely, absorption of solar radiation by ozone in the Hartley, Huggins, Chappuis, and Wulf bands, and by molecular oxygen in the Schumann-Runge continuum and $\mathrm{H}$ Lyman- $\alpha$ line; (ii) processes of resonant absorption of solar radiation. The resonant absorption of solar radiation in bands with centers of $0.762,0.688,0.629$, and $1.27 \mu \mathrm{m}$ leads to direct excitation of the $\mathrm{O}_{2}\left(\mathrm{~b}^{1} \Sigma^{+} \mathrm{g}, \mathrm{v}=0,1,2\right)$ and $\mathrm{O}_{2}\left(\mathrm{a}^{1} \Delta_{\mathrm{g}}, \mathrm{v}=0\right)$, respectively. The rates of these processes are tabulated in $[36,37]$ and traditionally denoted by $g_{\alpha}, g_{\beta}, g_{\gamma}$, and $g_{I R a}$.

Basic details of this mechanism became clear in the end of 1970s $[4,7,8,38]$ etc. Photolysis of oxygen molecules leads to formation of excited oxygen atoms $\mathrm{O}\left({ }^{1} \mathrm{D}\right)$ due to absorption of solar radiation in the Schumann-Runge continuum, which dominates at altitudes above $90 \mathrm{~km}$, and in the H Lyman- $\alpha$ line whose contribution is in the altitude range of $70-90 \mathrm{~km}$. Below $100 \mathrm{~km}$, another source of $\mathrm{O}\left({ }^{1} \mathrm{D}\right)$ formation is ozone photolysis in the Hartley band. As stated earlier [39], at least $90 \%$ of solar energy go through formation of excited atom $\mathrm{O}\left({ }^{1} \mathrm{D}\right)$ during $\mathrm{O}_{2}$ and $\mathrm{O}_{3}$ photolysis. Further, energy of $\mathrm{O}\left({ }^{1} \mathrm{D}\right)$ (threshold of excitation of $1.967 \mathrm{eV})$ is spent on excitation of $\mathrm{O}_{2}\left(\mathrm{~b}^{1} \Sigma^{+} \mathrm{g}, \mathrm{v}<2\right)$ levels. Figure 1 presents the mechanism of energy transfer between excited oxygen components in the atmosphere.

Note that not only energy transfer from $\mathrm{O}_{2}\left(b^{1} \Sigma^{+}{ }_{g}, v<2\right)$ levels is a source of $\mathrm{O}_{2}\left(a^{1} \Delta_{g}, v \leq 3\right)$ excitation. In the mesosphere, there is one more important source of excitation for $\mathrm{O}_{2}\left(\mathrm{a}^{1} \Delta_{\mathrm{g}}, \mathrm{v} \leq 5\right)$ levels, namely, singlet channel of ozone photolysis in the Hartley band. Despite many studies still supposing that only $\mathrm{O}_{2}\left(\mathrm{a}^{1} \Delta_{\mathrm{g}}, \mathrm{v}=0\right)$ level forms in this case, numerous laboratory experiments from 1980 to the present show simultaneous excitation of $\mathrm{O}_{2}\left(\mathrm{a}^{1} \Delta_{\mathrm{g}}, \mathrm{v}\right)$ levels with $\mathrm{v}$ up to 5 . Only after energy transfer from these levels, does the final population of $\mathrm{O}_{2}\left(\mathrm{a}^{1} \Delta_{\mathrm{g}}, \mathrm{v}=0\right)$ level occur. 
In addition, emission (optical) transitions from each of $\mathrm{O}_{2}\left(\mathrm{a}^{1} \Delta_{\mathrm{g}}, \mathrm{v}\right)$ and $\mathrm{O}_{2}\left(\mathrm{~b}^{1} \Sigma^{+} \mathrm{g}, \mathrm{v}\right)$ levels to the lower $\mathrm{O}_{2}\left(\mathrm{X}^{3} \Sigma_{\mathrm{g}}{ }^{-}, \mathrm{v}\right)$ levels are possible (Figure 1). Traditionally, transitions from these levels are grouped based on the upper excited state. Thus, the transitions $\mathrm{O}_{2}\left(\mathrm{~b}^{1} \Sigma_{\mathrm{g}}{ }^{+}, \mathrm{v}^{\prime} \rightarrow \mathrm{X}^{3} \Sigma_{\mathrm{g}}{ }^{-}, \mathrm{v}^{\prime \prime}\right)$ are called the system of atmospheric bands, and the transitions $\mathrm{O}_{2}\left(\mathrm{a}^{1} \Delta_{\mathrm{g}}, \mathrm{v}^{\prime} \rightarrow \mathrm{X}^{3} \Sigma_{\mathrm{g}}{ }^{-}, \mathrm{v}^{\prime \prime}\right)$ form the system of IR atmospheric bands. In these systems, transitions $\left(\mathrm{v}^{\prime}=0 \rightarrow \mathrm{v}^{\prime \prime}=0\right)$ corresponding to the wavelengths of $762 \mathrm{~nm}$ and $1270 \mathrm{~nm}$, respectively, are dominant. However, transitions from other vibrational levels are also observed as has been mentioned above. The altitude profiles of volume emission rates (VER) in these transitions let us determine the populations of excited levels of $\mathrm{O}_{2}\left(\mathrm{~b}^{1} \Sigma^{+} \mathrm{g}, \mathrm{v}\right)$ and $\mathrm{O}_{2}\left(\mathrm{a}^{1} \Delta_{\mathrm{g}}, \mathrm{v}\right)$ molecules. That, in turn, allows to track all stages of energy transfer from the upper excited levels to the ground state of oxygen molecules. To model the mechanism shown at Figure 1, we need to know the Einstein coefficients for emission transitions and have a database of rate coefficients for reactions of energy transfer and quenching of excited oxygen components in collisions with the main atmospheric components, namely, $\mathrm{O}_{2}, \mathrm{~N}_{2}, \mathrm{O}_{3}, \mathrm{O}\left({ }^{3} \mathrm{P}\right), \mathrm{CO}_{2}$. The role of the other small atmospheric components is neglectable in collisional processes [35].

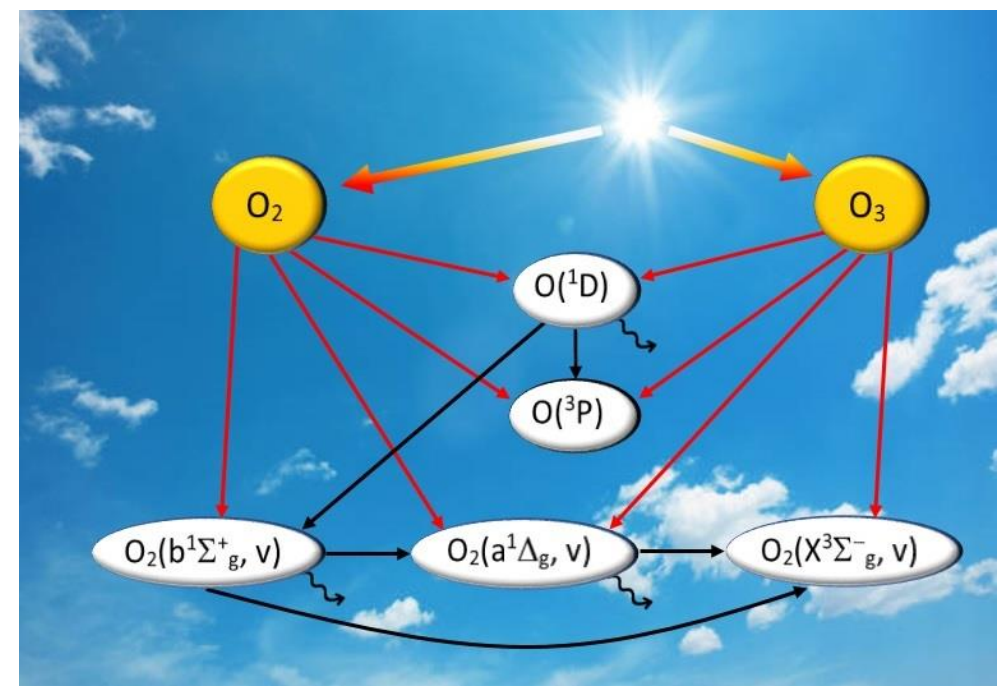

Figure 1. Block-scheme of electronically-vibrationally excited oxygen molecules formation in the daytime mesosphere and lower thermosphere. Red solid lines represent products of $\mathrm{O}_{2}$ and $\mathrm{O}_{3}$ photolysis, black solid lines show energy transfer as a result of collisional reactions, wave arrows correspond to emission transitions.

\section{1. $\mathrm{O}_{3}$ Photodissociation and Its Products}

As has been mentioned, there are two channels of $\mathrm{O}_{3}$ photodissociation:

(i) singlet channel $\mathrm{O}_{3}+h v(\lambda=200-320 \mathrm{~nm}) \rightarrow \mathrm{O}_{2}\left(\mathrm{a}^{1} \Delta_{\mathrm{g}}, \mathrm{v}=0-5\right)+\mathrm{O}\left({ }^{1} \mathrm{D}\right)$ in Hartley band;

(ii) triplet channel $\mathrm{O}_{3}+h v(\lambda=200-900 \mathrm{~nm}) \rightarrow \mathrm{O}_{2}\left(\mathrm{X}^{3} \Sigma^{-} \mathrm{g}, \mathrm{v}=0-35\right)+\mathrm{O}\left({ }^{3} \mathrm{P}\right)$ in Hartley, Huggins, Chappuis and Wulf bands.

In this subsection we will focus on the singlet channel since the dependence of $\mathrm{O}_{2}\left(\mathrm{X}^{3} \Sigma^{-} \mathrm{g}, \mathrm{v} \leq 35\right)$ quantum yields in triplet channel on wavelength has already been studied by Svanberg et al. [40] (Figure 2). Experimental studies of quantum yield in singlet channel for fixed wavelengths have also been performed [41-44], however, statistical processing of the results was not carried out. Note, that discrete data are not convenient for analytical studies, as these data require further interpolation. Therefore, here we will shortly consider analytical description of $\mathrm{O}_{2}\left(\mathrm{a}^{1} \Delta_{\mathrm{g}}, \mathrm{v}\right)$ quantum yields in singlet channel of ozone photolysis depending on wavelength. More detailed description of this analytical approach can be found in [45-47]. 


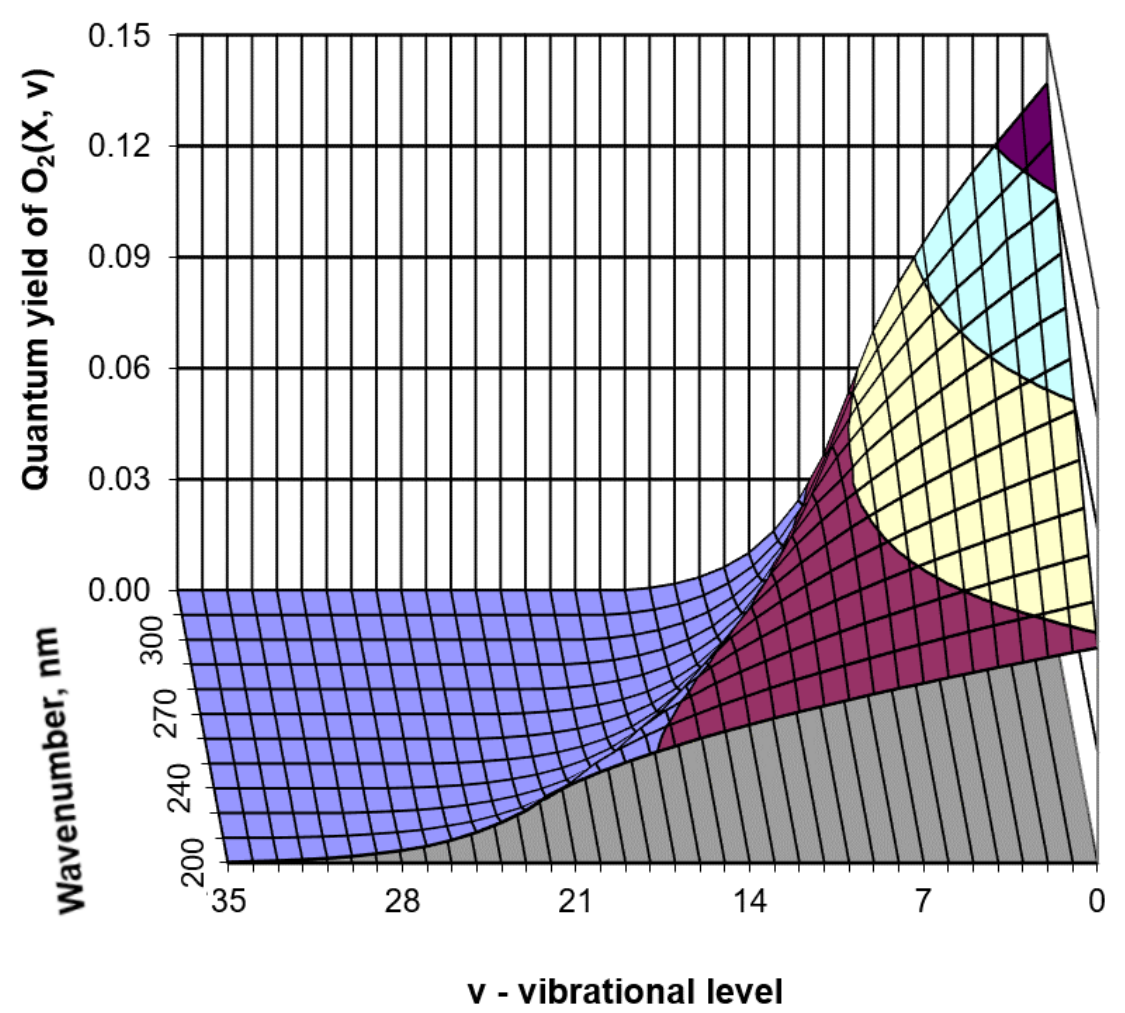

Figure 2. Quantum yields of $\mathrm{O}_{2}\left(\mathrm{X}^{3} \Sigma_{\mathrm{g}}{ }^{-}, \mathrm{v}=0-35\right)$ formation in the triplet channel of ozone photolysis depending on wavelength [40]. Colors correspond to subintervals of quantum yield values: violet (0.00-0.03), dark red (0.03-0.06), yellow (0.06-0.09), blue (0.09-0.12), purple (0.12-0.15).

The feature of photodissociation is changing of photolysis products and quantum yields depending on wavelength. Thus, there are threshold wavelengths starting from which oxygen molecules $\mathrm{O}_{2}\left(\mathrm{X}^{3} \Sigma^{-} \mathrm{g}\right.$, $\mathrm{v})$ and $\mathrm{O}_{2}\left(\mathrm{a}^{1} \Delta_{\mathrm{g}}, \mathrm{v}\right)$ with higher vibrational level $\mathrm{v}$ are formed (Table 1$)$.

Table 1. Threshold wavelengths $\lambda$ used to calculate threshold value of $x$ and normalization factors $C_{v}$.

\begin{tabular}{ccccccc}
\hline $\begin{array}{c}\text { Products of } \mathbf{O}_{3} \text { Photodissociation } \\
\text { in Hartley Band }\end{array}$ & $\mathbf{v}=\mathbf{0}$ & $\mathbf{v}=\mathbf{1}$ & $\mathbf{v}=\mathbf{2}$ & $\mathbf{v}=\mathbf{3}$ & $\mathbf{v}=\mathbf{4}$ & $\mathbf{v}=\mathbf{5}$ \\
\cline { 2 - 7 } & 310 & 296 & 284 & 273 & 263 & 254 \\
& 0.937 & 0.689 & 0.576 & 0.483 & 0.407 & 0.339 \\
Threshold wavelength, $\mathrm{nm}$ & 1.068 & 1.233 & 0.564 & 0.375 & 0.377 & 0.473 \\
Threshold value of $\boldsymbol{x}$ & $C_{v}$ & &
\end{tabular}

The energy mismatch of the reaction (i) can be written as:

$$
\Delta E=E-E_{\mathrm{DissO} 3}-E_{\mathrm{O}(1 \mathrm{D})}-E_{\mathrm{O} 2(\mathrm{a}, \mathrm{v}=0)},
$$

where $E$ is the energy of photon, $E_{\mathrm{Diss}}$ is the energy of ozone dissociation $(1.05 \mathrm{eV}), E_{\mathrm{O}(1 \mathrm{D})}$ is the energy of $\mathrm{O}\left({ }^{1} \mathrm{D}\right)$ excitation with respect to the ground state $(1.967 \mathrm{eV})$, and $E_{\mathrm{O} 2(\mathrm{a}, \mathrm{v}=0)}$ is the energy of $\mathrm{O}_{2}\left(\mathrm{a}^{1} \Delta_{\mathrm{g}}, \mathrm{v}=0\right)$ excitation with respect to the ground state $(0.977 \mathrm{eV})$.

Next, we introduce the parameter $x$ determining the fraction of $\mathrm{O}_{2}\left(\mathrm{a}^{1} \Delta_{\mathrm{g}}, \mathrm{v}\right)$ molecules which have energy above the excitation threshold of the $\mathrm{O}_{2}\left(\mathrm{a}^{1} \Delta_{\mathrm{g}}, \mathrm{v}=0\right)$ level:

$$
x=\exp \left(-\frac{\Delta E}{E_{O 2(a, v=0)}}\right)
$$


Then, the quantum yield of $\mathrm{O}_{2}\left(a^{1} \Delta_{g}, v\right)$ is determined by the fraction of energy that goes to the excitation of this level, depending on the wavelength and can be calculated by formulas:

$$
\begin{gathered}
F_{a, 0}(x)=C_{0} x \text { for } \mathrm{v}=0 \\
F_{a, v}(x)=C_{v} x\left(1-x-\frac{x^{2}}{2}-\frac{x^{3}}{2^{2}}-\cdots-\frac{x^{v}}{2^{v-1}}\right) \text { for } \mathrm{v} \geq 1
\end{gathered}
$$

where $C_{v}$ are normalization factors which have been calculated based on condition that the sum of quantum yields of all vibrationally excited $\mathrm{O}_{2}\left(\mathrm{a}^{1} \Delta_{\mathrm{g}}, \mathrm{v}\right)$ molecules equals 1 (Table 1$)$. Each normalization factor was calculated at a threshold energy value starting from which an oxygen molecule with the next vibrational level is formed during photolysis ( $x$ in Table 1 and the upper scale of Figure 3). Figure 3 represents the comparison of all currently known experimental values of $\mathrm{F}_{a, v}$ (symbols) with calculations by Equations (3) and (4) (solid lines). It is clearly seen from Figure 3 that molecules $\mathrm{O}_{2}\left(\mathrm{a}^{1} \Delta_{\mathrm{g}}, \mathrm{v}=0-5\right)$ are formed simultaneously at the peak of the Hartley band cross section absorption (wavelength of $\sim 254 \mathrm{~nm}$ ). Moreover, the quantum yield of $\mathrm{O}_{2}\left(\mathrm{a}^{1} \Delta_{\mathrm{g}}, \mathrm{v}=0\right)$ formation does not exceed $45 \%$.

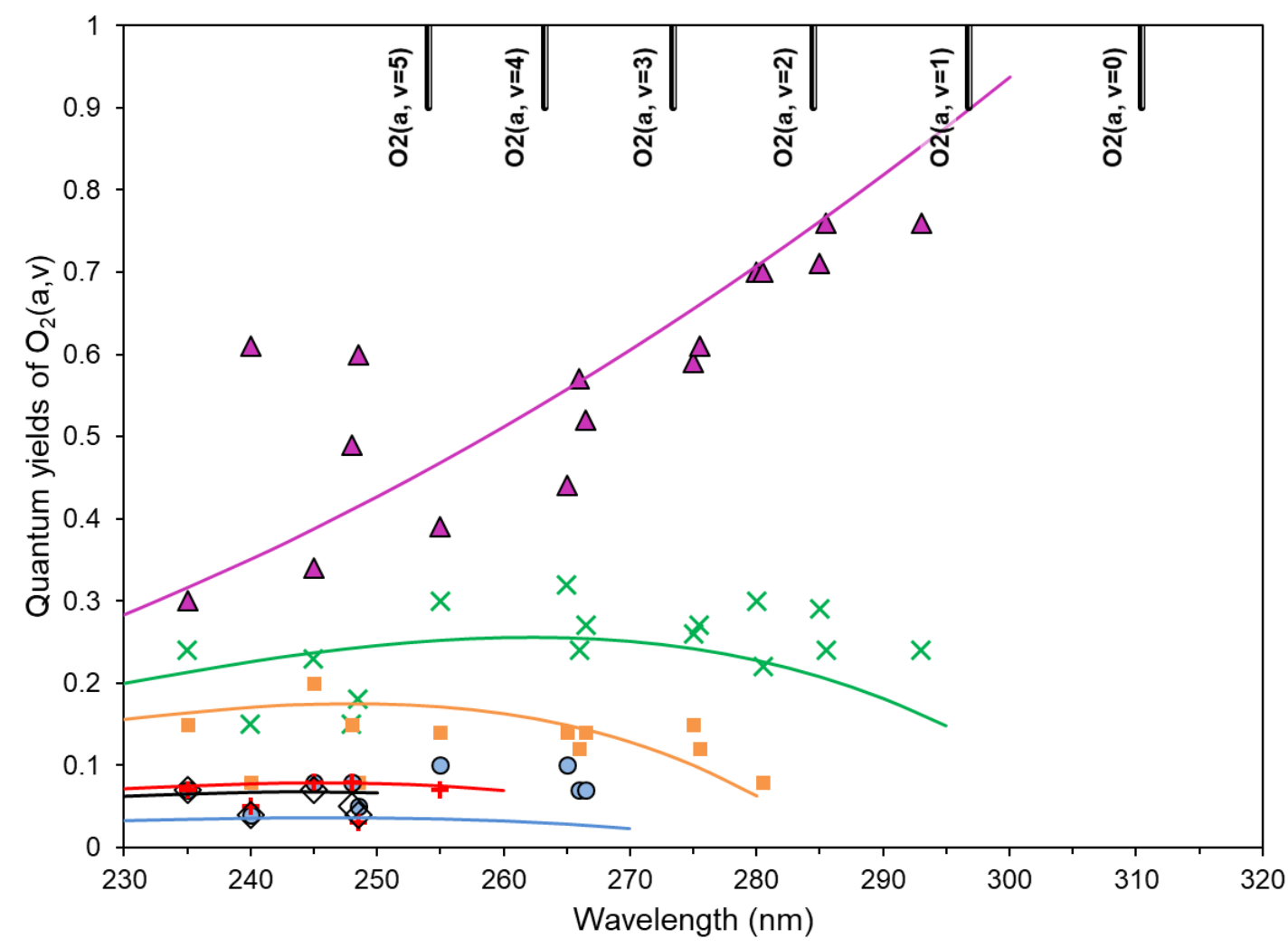

Figure 3. Quantum yields of $\mathrm{O}_{2}\left(\mathrm{a}^{1} \Delta_{\mathrm{g}}, \mathrm{v}=0-5\right)$, which are produced in result of the $\mathrm{O}_{3}$ photolysis in Hartley band. Experimental data: violet triangles $(\mathrm{v}=0)$, green crosses $(\mathrm{v}=1)$, orange squares $(\mathrm{v}=2)$, blue circles $(\mathrm{v}=3)$, red pluses $(\mathrm{v}=4)$ and black diamond $(\mathrm{v}=5)$. Calculations by Equations (3) and (4) for different $\mathrm{v}$ are solid lines with corresponding colors.

\subsection{Energy Transfer in Collisional Reactions}

Summarizing the discussion above the following may be stated. (1) An excited $\mathrm{O}\left({ }^{1} \mathrm{D}\right)$ atom and oxygen molecules in the states $\mathrm{O}_{2}\left(\mathrm{a}^{1} \Delta_{\mathrm{g}}, \mathrm{v}=0-5\right)$ and $\mathrm{O}_{2}\left(\mathrm{~b}^{1} \Sigma_{\mathrm{g}}{ }^{+}, \mathrm{v}=0-2\right)$ are formed as a result of photolysis. (2) Further, the energy of these excited levels is transferred to the lower excited levels of the oxygen molecule as a result of radiation and collision processes (see Figure 1). Note, however, that reaction rate coefficients involving electronically-vibrationally excited molecules are difficult for experimental measurements by traditional methods. 
Progress in building a new model of electronic-vibrational kinetics of oxygen components began in the late $90 \mathrm{~s}$-early $2000 \mathrm{~s}$. At first, the coefficient of vibrational-vibrational relaxation of the oxygen molecule ground electronic state $\mathrm{O}_{2}\left(\mathrm{X}^{3} \Sigma^{-} \mathrm{g}, \mathrm{v}\right)$ in the reaction

$$
\mathrm{O}_{2}\left(\mathrm{X}^{3} \Sigma^{-} \mathrm{g}, \mathrm{v}^{\prime} \leq 13\right)+\mathrm{O}_{2} \rightarrow \mathrm{O}_{2}\left(\mathrm{X}^{3} \Sigma^{-} \mathrm{g}, \mathrm{v}^{\prime}-1\right)+\mathrm{O}_{2}\left(\mathrm{X}^{3} \Sigma^{-} \mathrm{g}, \mathrm{v}=1\right)
$$

was measured by Klatt et al. [48] and was calculated by Hernandez et al. [49]. It has been shown that the rate coefficient of reaction (5) decreases with an increase of the vibrational number.

In 1994, another interesting result was obtained by Park and Slanger [29], namely, a sharp resonant increase of the reaction (6) rate for $\mathrm{v}^{\prime}=14-25$ due to the transfer of energy of two vibrational quanta of an oxygen molecule to one vibrational quantum of a nitrogen molecule.

$$
\mathrm{O}_{2}\left(\mathrm{X}^{3} \Sigma^{-} \mathrm{g}, \mathrm{v}^{\prime}=14-25\right)+\mathrm{N}_{2} \rightarrow \mathrm{O}_{2}\left(\mathrm{X}^{3} \Sigma^{-} \mathrm{g}, \mathrm{v}^{\prime}-2\right)+\mathrm{N}_{2}\left(\mathrm{X}^{1} \Sigma_{\mathrm{g}}{ }^{+}, \mathrm{v}=1\right)
$$

The fact is that for such $\mathrm{v}^{\prime}$ values in reaction (6), the energy transfer from the oxygen molecule to the nitrogen molecule has an almost resonant character. In both (5) and (6) cases, it is obvious that a change in the reaction rate coefficient with a change in $\mathrm{v}$ is associated with a defect of the reaction energy (see Figure 4 where both experimental data [29,48,50-54] and theoretical estimates [55] are presented). The smaller defect of energy, the greater the reaction rate coefficient. Figure 4 shows rate coefficients of the reactions (5)-(6) depending on module of energy mismatch.

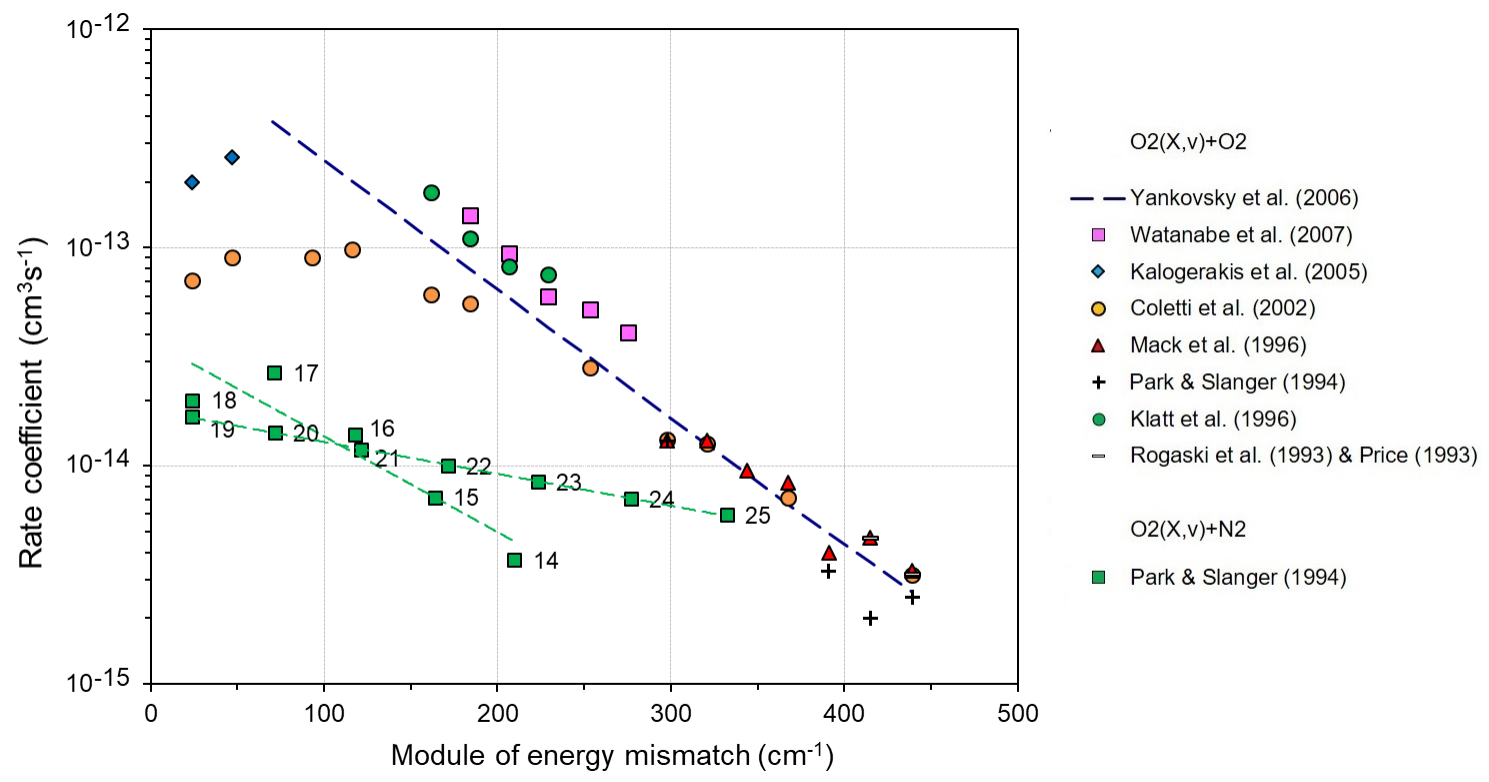

Figure 4. Rate coefficients of $\mathrm{O}_{2}\left(\mathrm{X}^{3} \Sigma_{\mathrm{g}}{ }^{-}, \mathrm{v}\right)+\mathrm{O}_{2} \rightarrow$ products $[29,32,48,50-55]$ and $\mathrm{O}_{2}\left(\mathrm{X}^{3} \Sigma_{\mathrm{g}}{ }^{-}, \mathrm{v}\right)+\mathrm{N}_{2}$ $\rightarrow$ products [29] depending on module of energy mismatch. The numbers indicate values of the vibrational quantum.

Since 1998, a series of experiments was begun at the Molecular Physics Laboratory (MPL), SRI International (Space Research Institute) to measure rate coefficients of reactions involving electronically vibrationally excited oxygen molecules in the two singlet states, $\mathrm{O}_{2}\left(\mathrm{~b}^{1} \Sigma_{\mathrm{g}}{ }^{+}, \mathrm{v} \geq 1\right)$ and $\mathrm{O}_{2}\left(\mathrm{a}^{1} \Delta_{\mathrm{g}}, \mathrm{v} \geq 1\right)$, in collisions with atomic and molecular oxygen, as well as with nitrogen. As a result of the experiments, it was found that the rate coefficients of these reactions have abnormally high values close to the gas-kinetic reaction rates [56-59] etc. In a certain sense, this was a kind of surprise, since the reaction rate coefficients for singlet levels of oxygen molecule without vibrational excitation were low. For example, reaction rate coefficients for

$$
\mathrm{O}_{2}\left(\mathrm{a}^{1} \Delta_{\mathrm{g}}, \mathrm{v}=0\right)+\mathrm{O}_{2} \rightarrow \text { products }
$$




$$
\mathrm{O}_{2}\left(\mathrm{~b}^{1} \Sigma_{\mathrm{g}}{ }^{+}, \mathrm{v}=0\right)+\mathrm{O}_{2} \rightarrow \text { products }
$$

have values of $k\left(\mathrm{O}_{2}(\mathrm{a}, \mathrm{v}=0) ; \mathrm{O}_{2}\right)=3 \times 10^{-18} \mathrm{~cm}^{3} \mathrm{~s}^{-1}$ and $k\left(\mathrm{O}_{2}(\mathrm{~b}, \mathrm{v}=0) ; \mathrm{O}_{2}\right)=4 \times 10^{-17} \mathrm{~cm}^{3} \mathrm{~s}^{-1}[60]$. The MPL laboratory staff were able to explain the sharp acceleration of the reactions for $\mathrm{v} \geq 1$ by the fact that these reactions proceed through the channel of electron-vibrational exchange, namely,

$$
\begin{gathered}
\mathrm{O}_{2}\left(\mathrm{a}^{1} \Delta_{\mathrm{g}}, \mathrm{v}^{\prime}\right)+\mathrm{O}_{2}\left(\mathrm{X}^{3} \Sigma^{-} \mathrm{g}, \mathrm{v}^{\prime \prime}=0\right) \rightarrow \mathrm{O}_{2}\left(\mathrm{X}^{3} \Sigma^{-} \mathrm{g}, \mathrm{v}^{\prime}\right)+\mathrm{O}_{2}\left(\mathrm{a}^{1} \Delta_{\mathrm{g}}, \mathrm{v}^{\prime \prime}=0\right) \\
\mathrm{O}_{2}\left(\mathrm{~b}^{1} \Sigma_{\mathrm{g}}{ }^{+}, \mathrm{v}^{\prime}\right)+\mathrm{O}_{2}\left(\mathrm{X}^{3} \Sigma^{-} \mathrm{g}^{-} \mathrm{v}^{\prime \prime}=0\right) \rightarrow \mathrm{O}_{2}\left(\mathrm{X}^{3} \Sigma^{-} \mathrm{g}, \mathrm{v}^{\prime}\right)+\mathrm{O}_{2}\left(\mathrm{~b}^{1} \Sigma_{\mathrm{g}}{ }^{+}, \mathrm{v}^{\prime \prime}=0\right)
\end{gathered}
$$

A feature of these reactions is that the quantum of electronic excitation is transmitted to the partner through a collision, and the quantum of vibrational excitation is "frozen" as it is. These reactions have an energy defect in the range of $0-250 \mathrm{~cm}^{-1}$. Typical rate coefficients of these reactions for $\mathrm{v}=1,2,3$ have values of $(0.5-5.0) \times 10^{-11} \mathrm{~cm}^{3} \mathrm{~s}^{-1}$, that is, they are only several times lower than the gas-kinetic rate of the chemical reaction (see Figure 5). Another feature of these reactions is that, with an increase of vibrational excitation, the rate coefficients of these reactions usually begin to decline (see Figure 5).

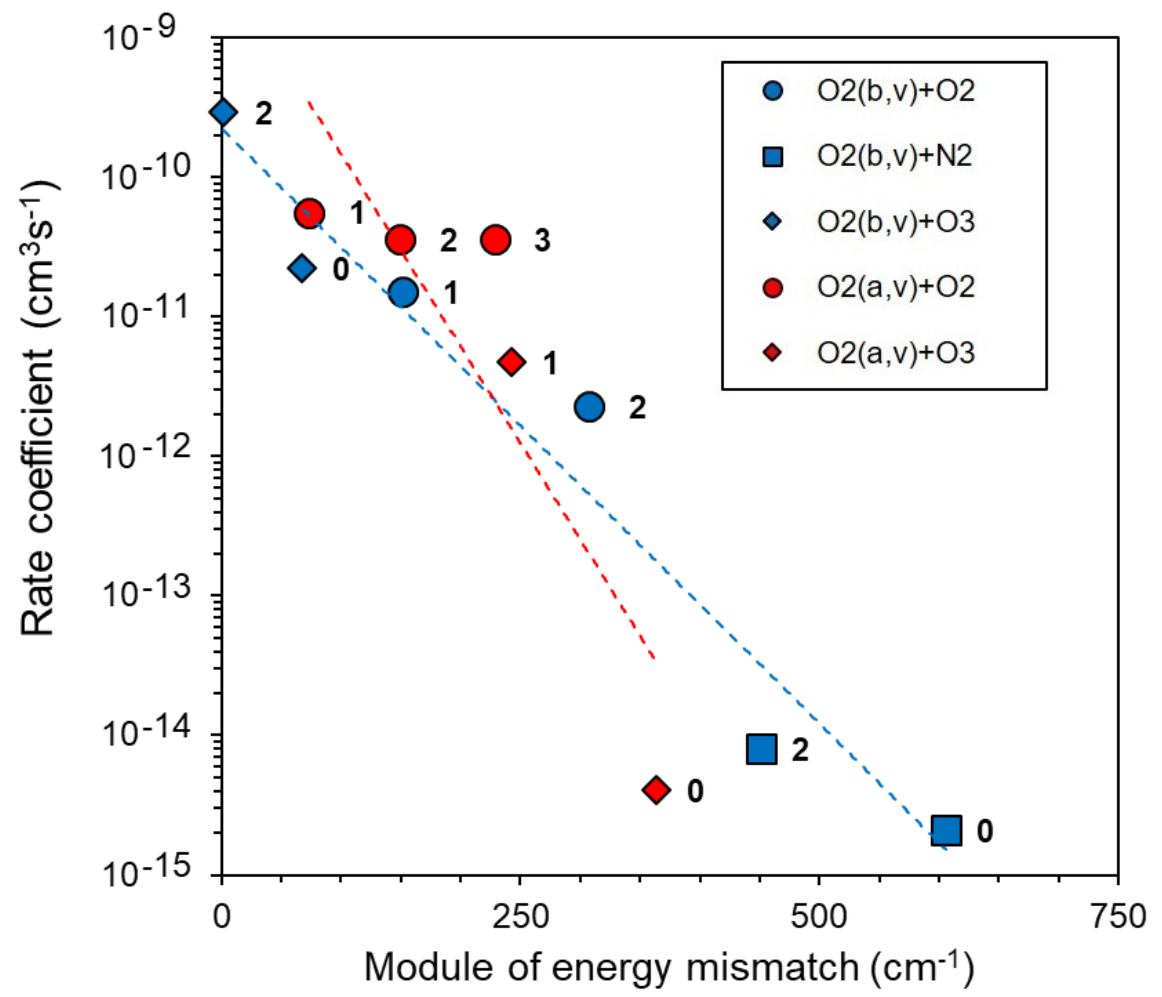

Figure 5. The same as Figure 4 but for $\mathrm{O}_{2}\left(\mathrm{~b}^{1} \Sigma_{\mathrm{g}}{ }^{+}, \mathrm{v}\right)+\mathrm{O}_{2} \rightarrow$ products (blue circles), $\mathrm{O}_{2}\left(\mathrm{~b}^{1} \Sigma_{\mathrm{g}}{ }^{+}, \mathrm{v}\right)+$ $\mathrm{N}_{2} \rightarrow$ products (blue squares), $\mathrm{O}_{2}\left(\mathrm{~b}^{1} \Sigma_{\mathrm{g}}{ }^{+}, \mathrm{v}\right)+\mathrm{O}_{3} \rightarrow$ products (blue diamonds), $\mathrm{O}_{2}\left(\mathrm{a}^{1} \Delta_{\mathrm{g}}, \mathrm{v}\right)+\mathrm{O}_{2} \rightarrow$ products (red circles), $\mathrm{O}_{2}\left(\mathrm{a}^{1} \Delta_{\mathrm{g}}, \mathrm{v}\right)+\mathrm{O}_{3} \rightarrow$ products (red diamonds) [2].

It would be natural to expect that a similar effect should be observed in collisional reactions with ozone. Indeed, the rate coefficients measured at room temperature are $k\left(\mathrm{O}_{2}(\mathrm{a}, \mathrm{v}=0) ; \mathrm{O}_{3}\right)=4 \times 10^{-15}$ $\mathrm{cm}^{3} \mathrm{~s}^{-1}$ for $\mathrm{O}_{2}\left(\mathrm{a}^{1} \Delta_{\mathrm{g}}, \mathrm{v}=0\right)$ and $k\left(\mathrm{O}_{2}(\mathrm{a}, \mathrm{v}=1) ; \mathrm{O}_{3}\right)=5 \times 10^{-12} \mathrm{~cm}^{3} \mathrm{~s}^{-1}$ for $\mathrm{O}_{2}\left(\mathrm{a}^{1} \Delta_{\mathrm{g}}, \mathrm{v}=1\right)$. A similar dependence of the reaction rate coefficient on the energy defect is also observed for collisional reactions of $\mathrm{O}_{2}\left(\mathrm{~b}^{1} \Sigma_{\mathrm{g}}{ }^{+}, \mathrm{v}=0\right)$ with ozone (Figure 5):

$$
\begin{gathered}
\mathrm{O}_{2}\left(\mathrm{~b}^{1} \Sigma_{\mathrm{g}}{ }^{+}, \mathrm{v}=0\right)+\mathrm{O}_{3} \rightarrow \mathrm{O}_{2}\left(\mathrm{a}^{1} \Delta_{\mathrm{g}}, \mathrm{v}=0\right)+\mathrm{O}_{3}(302)+67.6 \mathrm{~cm}^{-1} \\
\mathrm{O}_{2}\left(\mathrm{~b}^{1} \Sigma_{\mathrm{g}}{ }^{+}, \mathrm{v}=2\right)+\mathrm{O}_{3} \rightarrow \mathrm{O}_{2}\left(\mathrm{a}^{1} \Delta_{\mathrm{g}}, \mathrm{v}=2\right)+\mathrm{O}_{3}(203)+2.0 \mathrm{~cm}^{-1}
\end{gathered}
$$


Of particular interest are the collisional reactions of electronically-vibrationally excited oxygen molecules with atomic oxygen. To date, the products of these reactions are not known, however, their rate coefficients have a rather large scatter of values (see Table 2). Such a spread of values can be explained if we assume that only a part of these reactions (the fastest) are quasi-resonant. For example, in Table 2 we offer possible products of a number of reactions and energy defects corresponding to these channels. So, the first very fast reaction is apparently quasi-resonant, as a result of which the energy of the $\mathrm{O}_{2}\left(\mathrm{~b}^{1} \Sigma_{\mathrm{g}}{ }^{+}, \mathrm{v}=2\right)$ molecule, as we believe, is transferred to the $\mathrm{O}\left({ }^{1} \mathrm{D}\right)$ atom. The energy defect of this reaction in this channel is only $37.6 \mathrm{~cm}^{-1}$ (or $54 \mathrm{~K}$ ). In passing, we note that at higher kinetic temperatures of the gas, a quasi-resonant process in the reverse reaction may be possible

$$
\mathrm{O}\left({ }^{1} \mathrm{D}\right)+\mathrm{O}_{2} \rightarrow \mathrm{O}\left({ }^{3} \mathrm{P}\right)+\mathrm{O}_{2}\left(\mathrm{~b}^{1} \Sigma_{\mathrm{g}}{ }^{+}, \mathrm{v}=2\right)-37.6 \mathrm{~cm}^{-1}
$$

The results of a laboratory experiment suggest this idea [61].

A high value of the rate coefficient for the second reaction in Table 2 can be, presumably, due to the fact that the energy transfer goes to the excitation of oxygen molecules with the vibrational level $\mathrm{v}=10$. However, this assumption requires experimental confirmation. For the last two reactions in Table 2 with low values of the rate coefficients, it was not possible to find quasi-resonant energy transfer channels.

Table 2. Possible correlation between a reaction energy mismatch and value of the rate coefficient at thermal temperatures.

\begin{tabular}{ccccc}
\hline No. & Reaction & $\begin{array}{c}\text { Rate Coefficient, } \\
\mathbf{c m}^{\mathbf{3}} \mathbf{s}^{\mathbf{- 1}}[2]\end{array}$ & $\begin{array}{c}\text { Supposed Products of } \\
\text { Reaction }\end{array}$ & $\begin{array}{c}\text { Energy Mismatch, } \\
\mathbf{c m}^{\mathbf{- 1}}\end{array}$ \\
\hline 1 & $\mathrm{O}_{2}\left(\mathrm{~b}^{1} \Sigma_{\mathrm{g}}{ }^{+}, \mathrm{v}=2\right)+\mathrm{O}\left({ }^{3} \mathrm{P}\right) \rightarrow$ & $1.07 \times 10^{-11}$ & $\mathrm{O}_{2}+\mathrm{O}\left({ }^{1} \mathrm{D}\right)$ & 37.6 \\
2 & $\mathrm{O}_{2}\left(\mathrm{~b}^{1} \Sigma_{\mathrm{g}}{ }^{+}, \mathrm{v}=1\right)+\mathrm{O}\left({ }^{3} \mathrm{P}\right) \rightarrow$ & $4.5 \times 10^{-12}$ & $\mathrm{O}_{2}\left(\mathrm{X}^{3} \Sigma_{\mathrm{g}}{ }^{-}, \mathrm{v}=10\right)+\mathrm{O}\left({ }^{3} \mathrm{P}\right)$ & 2.3 \\
3 & $\mathrm{O}_{2}\left(\mathrm{~b}^{1} \Sigma_{\mathrm{g}}{ }^{+}, \mathrm{v}=0\right)+\mathrm{O}\left({ }^{3} \mathrm{P}\right) \rightarrow$ & $8 \times 10^{-14}$ & $\mathrm{O}_{2}\left(\mathrm{a}^{1} \Delta_{\mathrm{g}}, \mathrm{v}=0\right)+\mathrm{O}\left({ }^{3} \mathrm{P}\right)$ & 5238.0 \\
4 & $\mathrm{O}_{2}\left(\mathrm{a}^{1} \Delta_{\mathrm{g}}, \mathrm{v}=0\right)+\mathrm{O}\left({ }^{3} \mathrm{P}\right) \rightarrow$ & $<3 \times 10^{-16}$ & $\mathrm{O}_{2}+\mathrm{O}\left({ }^{3} \mathrm{P}\right)$ & 7883.0 \\
\hline
\end{tabular}

It must be emphasized that at present, the rate coefficients of reactions involving atomic oxygen are measured with a very large error. For example, the rate coefficient of reaction 4 in Table 2 is known only as the upper limit, $k\left(\mathrm{O}_{2}(\mathrm{a}, \mathrm{v}=0) ; \mathrm{O}\left({ }^{3} \mathrm{P}\right)\right)<3 \times 10^{-16} \mathrm{~cm}^{3} \mathrm{~s}^{-1}[1]$, and the rate coefficient $k\left(\mathrm{O}_{2}(\mathrm{~b}\right.$, $\left.\mathrm{v}=0) ; \mathrm{O}\left({ }^{3} \mathrm{P}\right)\right)$ has a large relative error $\sim 400 \%[60]$.

To date, for only one reaction involving atomic oxygen, theoretical calculations of the reaction rate coefficient depending on the values of the vibrational quantum have been carried out, namely, for

$$
\mathrm{O}_{2}\left(\mathrm{X}^{3} \Sigma^{-} \mathrm{g}, \mathrm{v} \leq 30\right)+\mathrm{O}\left({ }^{3} \mathrm{P}\right) \rightarrow \mathrm{O}_{2}\left(\mathrm{X}^{3} \Sigma^{-} \mathrm{g}, \mathrm{v}^{\prime}=\mathrm{v}-\Delta \mathrm{v}\right)+\mathrm{O}\left({ }^{3} \mathrm{P}\right)
$$

Esposito et al. [62] calculated the values of the reaction (14) rate coefficients for $\Delta v=1-30$ (see Figure 6). This reaction turned out to be one of the keys for modeling population of $\mathrm{O}_{2}\left(\mathrm{X}^{3} \Sigma^{-} \mathrm{g}, \mathrm{v}^{\prime}=1\right)$ level in the MLT region [33,34]. A distinctive feature of this mechanism is that in order to populate the lower vibrational level $\mathrm{O}_{2}\left(\mathrm{X}^{3} \Sigma^{-} \mathrm{g}, \mathrm{v}^{\prime}=1\right)$, cascade transitions from all overlying levels $\mathrm{v}^{\prime}=2-30$ must be considered.

Using experimental studies [5,48,58,61,63-67] etc. as well as theoretical calculations by [62,68-70] we managed to create a database of the rate coefficients and quantum yields of reaction products with the participation of $\mathrm{O}_{2}\left(\mathrm{~b}^{1} \Sigma_{\mathrm{g}}{ }^{+}, \mathrm{v}\right), \mathrm{O}_{2}\left(\mathrm{a}^{1} \Delta_{\mathrm{g}}, \mathrm{v}\right), \mathrm{O}_{2}\left(\mathrm{X}^{3} \Sigma^{-} \mathrm{g}, \mathrm{v}\right)$ [33], (supplement in 2). This database was the basis of the model of electronic-vibrational kinetics of $\mathrm{O}_{2}$ and $\mathrm{O}_{3}$ photolysis products in the MLT region (YM2011 model). It is important to emphasize that for a significant part of reactions in the database, temperature dependence and the error range for the MLT temperature range are known. 


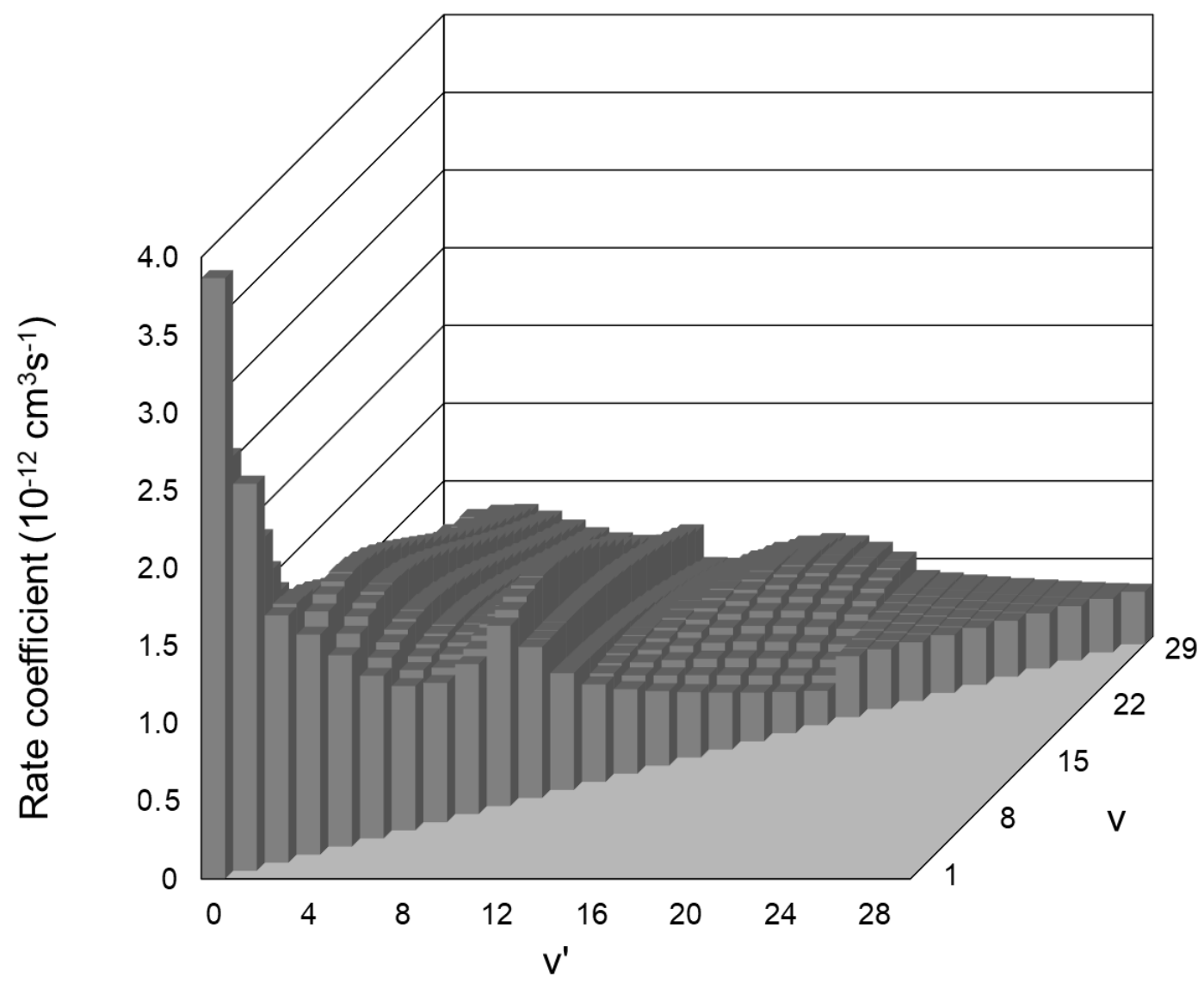

Figure 6. Rate coefficients of $\mathrm{O}_{2}\left(\mathrm{X}^{3} \Sigma_{\mathrm{g}}{ }^{-}, \mathrm{v} \leq 30\right)+\mathrm{O}\left({ }^{3} \mathrm{P}\right) \rightarrow \mathrm{O}_{2}\left(\mathrm{X}^{3} \Sigma_{\mathrm{g}}{ }^{-}, \mathrm{v}^{\prime}=\mathrm{v}-\Delta \mathrm{v}\right)+\mathrm{O}\left({ }^{3} \mathrm{P}\right)$ depending on $\mathrm{v}$ and $\mathrm{v}^{\prime}[62]$.

\subsection{Emission Transitions}

Emission transitions $\mathrm{O}_{2}\left(\mathrm{~b}^{1} \Sigma^{+}{ }_{\mathrm{g}}, \mathrm{v}^{\prime} \leq 10 \rightarrow \mathrm{X}^{3} \Sigma^{-}{ }_{\mathrm{g}}, \mathrm{v}^{\prime \prime}\right), \mathrm{O}_{2}\left(\mathrm{a}^{1} \Delta_{\mathrm{g}}, \mathrm{v}^{\prime} \leq 10 \rightarrow \mathrm{X}^{3} \Sigma^{-} \mathrm{g}, \mathrm{v}^{\prime \prime}\right)$ and $\mathrm{O}_{2}\left(\mathrm{~b}^{1} \Sigma^{+} \mathrm{g}\right.$, $\left.\mathrm{v}^{\prime} \leq 10 \rightarrow \mathrm{a}^{1} \Delta_{\mathrm{g}}, \mathrm{v}^{\prime \prime}\right)$ form the systems of $\mathrm{O}_{2}$ atmospheric, IR atmospheric, and Noxon bands, respectively. The population of an excited level is related with volume emission rate (VER) from this level to the lower level as the ratio of VER to the Einstein coefficient for the corresponding transition, $A_{E}$. Therefore, Einstein coefficients are necessary to calculate concentrations of the excited molecules $\mathrm{O}_{2}\left(\mathrm{~b}^{1} \Sigma^{+}{ }_{\mathrm{g}}, \mathrm{v}^{\prime} \geq 0\right)$ and $\mathrm{O}_{2}\left(\mathrm{a}^{1} \Delta_{\mathrm{g}}, \mathrm{v}^{\prime} \geq 0\right)$ in the MLT from measured VERs. In addition, Einstein coefficients are related to the radiative quenching which is the key process in the lower thermosphere.

Currently, there is no single database of Einstein coefficients for the aforementioned transitions in $\mathrm{O}_{2}$ bands, however, some attempts to define them from both measurements and theory have been made. Table 3 shows all values of the Einstein coefficients obtained in laboratory studies. Table 4 includes information about attempts to calculate the Einstein coefficients for last 50 years. The data incompleteness does not allow to sufficiently describe the radiative quenching in photochemical modelling. Therefore, Yankovsky et al. [2] presented an estimation of the Einstein coefficients for emission transitions in the $\mathrm{O}_{2}$ atmospheric, IR atmospheric, and Noxon bands based on values of the Franck-Condon factor from [71]. 
Table 3. Measured values of Einstein coefficient $\left(\mathrm{s}^{-1}\right)$ for $\mathrm{O}_{2}$ bands systems $[72,73]$.

\begin{tabular}{|c|c|c|c|c|c|c|c|c|}
\hline \multirow{2}{*}{ Transition. } & \multicolumn{2}{|c|}{$\mathbf{v}^{\prime}=0$} & \multicolumn{2}{|c|}{$\mathrm{v}^{\prime}=1$} & \multicolumn{2}{|c|}{$\mathrm{v}^{\prime}=2$} & \multicolumn{2}{|c|}{$\mathbf{v}^{\prime}=3$} \\
\hline & $\mathrm{v}^{\prime \prime}=0$ & $\mathrm{v}^{\prime \prime}=1$ & $\mathrm{v}^{\prime \prime}=0$ & $\mathrm{v}^{\prime \prime}=1$ & $\mathrm{v}^{\prime \prime}=0$ & $\mathrm{v}^{\prime \prime}=1$ & $\mathrm{v}^{\prime \prime}=0$ & $\mathrm{v}^{\prime \prime}=1$ \\
\hline $\begin{array}{c}\mathrm{O}_{2} \text { Atm band } \\
\left(\mathrm{v}^{\prime}-\mathrm{v}^{\prime \prime}\right)\end{array}$ & $8.93 \times 10^{-2}$ & $4.67 \times 10^{-3}$ & $7.20 \times 10^{-3}$ & $7.01 \times 10^{-2}$ & $2.69 \times 10^{-4}$ & & $6.73 \times 10^{-6}$ & \\
\hline $\begin{array}{c}\mathrm{O}_{2} \text { Noxon band } \\
\left(\mathrm{v}^{\prime}-\mathrm{v}^{\prime \prime}\right)\end{array}$ & $1.20 \times 10^{-3}$ & & & & & & & \\
\hline $\begin{array}{c}\mathrm{O}_{2} \text { IR Atm band } \\
\left(\mathrm{v}^{\prime}-\mathrm{v}^{\prime \prime}\right)\end{array}$ & $2.26 \times 10^{-4}$ & $2.81 \times 10^{-6}$ & & & & & & \\
\hline
\end{tabular}

Table 4. Calculations of Franck-Condon factor values.

\begin{tabular}{ccc}
\hline Details of Calculation. & Transitions & Reference \\
\hline \multirow{2}{*}{ Morse potential } & $\mathrm{O}_{2}\left(\mathrm{~b}, \mathrm{v}^{\prime} \leq 3 \leftrightarrow \mathrm{X}, \mathrm{v}^{\prime \prime} \leq 3\right)$ & \\
& $\mathrm{O}_{2}\left(\mathrm{~b}, \mathrm{v}^{\prime} \leq 3 \leftrightarrow \mathrm{a}, \mathrm{v}^{\prime \prime} \leq 5\right)$ & \\
& $\mathrm{O}_{2}\left(\mathrm{a}, \mathrm{v}^{\prime} \leq 5 \leftrightarrow \mathrm{X}, \mathrm{v}^{\prime \prime} \leq 6\right)$ & \\
\hline \multirow{2}{*}{ RKR potential } & $\mathrm{O}_{2}\left(\mathrm{~b}, \mathrm{v}^{\prime} \leq 3 \leftrightarrow \mathrm{X}, \mathrm{v}^{\prime \prime} \leq 8\right)$ \\
& $\mathrm{O}_{2}\left(\mathrm{a}, \mathrm{v}^{\prime} \leq 3 \leftrightarrow \mathrm{X}, \mathrm{v}^{\prime \prime} \leq 6\right)$ & {$[73]$} \\
\hline RKR potential & $\mathrm{O}_{2}\left(\mathrm{~b}, \mathrm{v}^{\prime} \leq 4 \leftrightarrow \mathrm{X}, \mathrm{v}^{\prime \prime} \leq 4\right)$ & {$[23]$} \\
\hline Transition moments from $[74]$ & $\mathrm{O}_{2}\left(\mathrm{~b}, \mathrm{v}^{\prime} \leq 10 \leftrightarrow \mathrm{X}, \mathrm{v}^{\prime \prime} \leq 9\right)$ & \\
\hline \multirow{2}{*}{ RKR potential } & $\mathrm{O}_{2}\left(\mathrm{~b}, \mathrm{v}^{\prime} \leq 10 \leftrightarrow \mathrm{X}, \mathrm{v}^{\prime \prime} \leq 35\right)$ \\
& $\mathrm{O}_{2}\left(\mathrm{~b}, \mathrm{v}^{\prime} \leq 10 \leftrightarrow \mathrm{a}, \mathrm{v}^{\prime \prime} \leq 15\right)$ & \\
\hline
\end{tabular}

The spectroscopic parameters of mentioned transitions were specified in laboratory experiments and theoretical calculations [72-81] etc. A part of the results is used in the last version of HITRAN (only for transitions from levels $\mathrm{v} \leq 2$ ).

Yankovsky et al. [2] calculated the Einstein coefficients $A_{v^{\prime} v^{\prime \prime}}$ using the formula from [82,83]:

$$
A_{\mathrm{v}^{\prime} \mathrm{v}^{\prime \prime}}=A_{00} \frac{q_{\mathrm{v}^{\prime} \mathrm{v}^{\prime \prime}} v_{\mathrm{v}^{\prime} \mathrm{v}^{\prime \prime}}^{3}}{q_{00} v_{00}^{3}}
$$

where $v_{v^{\prime} v^{\prime \prime}}$-transition energy in $\mathrm{cm}^{-1}, q_{v^{\prime} v^{\prime \prime}}$-Franck-Condon factor for transition from the level with vibrational number $\mathrm{v}^{\prime}$ to the level with vibrational number $\mathrm{v}^{\prime \prime}$, taken from [71]. Results of calculations by (15) for the atmospheric, Noxon, and IR atmospheric bands, respectively, are presented in [2].

The values of the Einstein coefficient for transitions from $v^{\prime}=0-10$ to $v^{\prime \prime}=0-14$ in the $\mathrm{O}_{2}$ atmospheric band [2] allow us to estimate the probability of radiative quenching for levels $\mathrm{O}_{2}\left(\mathrm{~b}^{1} \Sigma_{\mathrm{g}}{ }^{+}\right.$, $\mathrm{v}^{\prime}=0-10$ ) (Figure 7). Notice that our estimation of the radiative lifetime based on the Einstein coefficients from [2] is consistent with recent experimental estimates for vibrational levels $\mathrm{v}=0,1$. Differing from our calculation, the data from $[84,85]$ were estimated only on the basis of values for the fundamental transitions $\mathrm{O}_{2}\left(\mathrm{~b}^{1} \Sigma_{\mathrm{g}}{ }^{+}, \mathrm{v}^{\prime}=0,1 \rightarrow \mathrm{X}^{3} \Sigma^{-}{ }_{\mathrm{g}}, \mathrm{v}^{\prime \prime}=0,1\right)$ and do not take into account emission transitions to levels $\mathrm{v}^{\prime \prime}>1$. 


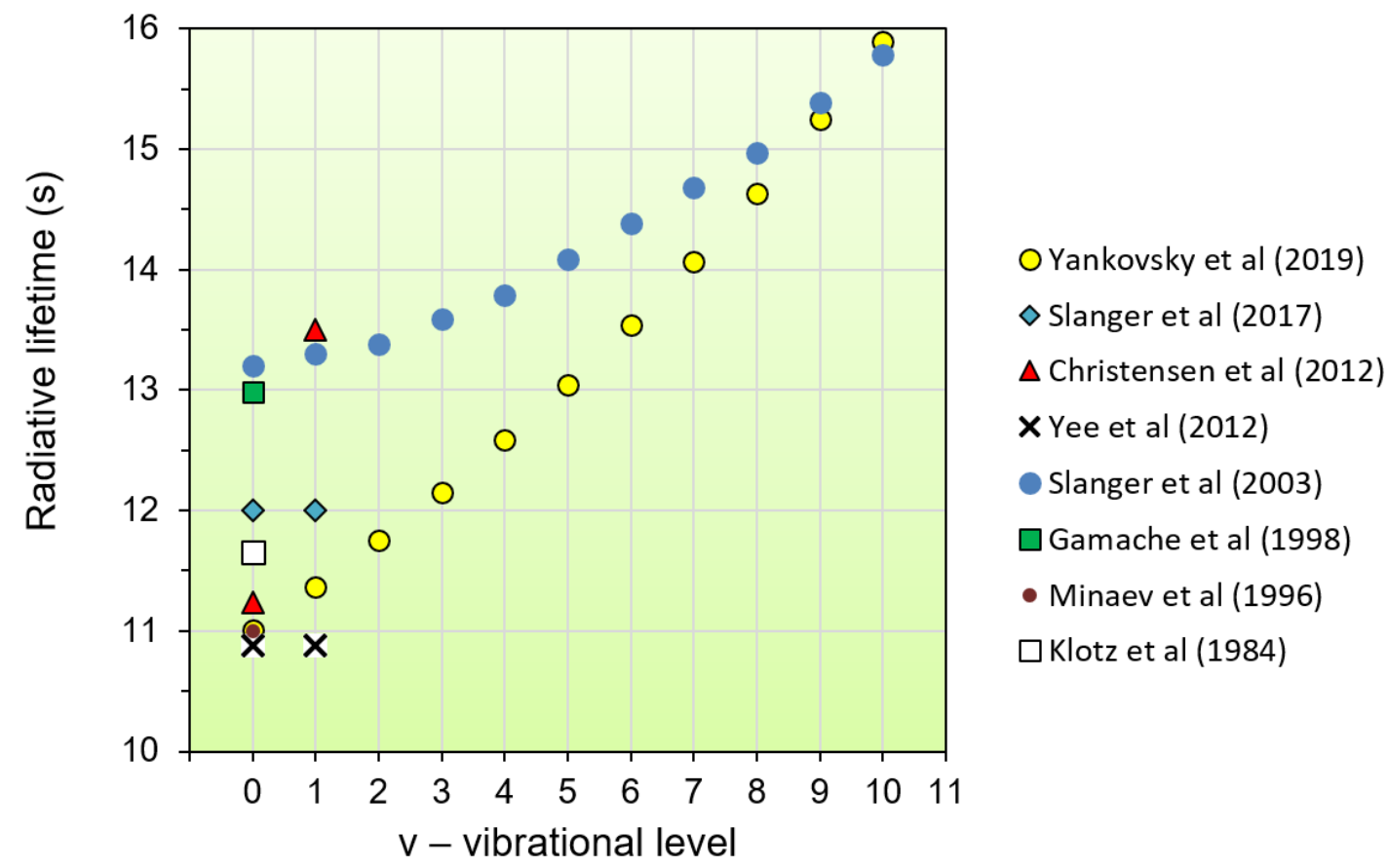

Figure 7. Currently known estimations of $\mathrm{O}_{2}\left(\mathrm{~b}^{1} \Sigma_{\mathrm{g}}{ }^{+}, \mathrm{v}=0-10\right)$ radiative lifetimes $[2,24,25,74,84-87]$.

\subsection{Another Mechanism of $\mathrm{O}_{2}\left(b^{1} \Sigma^{+}{ }_{g}, v=0\right)$ Excitation}

It should be noted that there is another source of energy in lower thermosphere - the association of oxygen atoms in the triple reaction

$$
\mathrm{O}\left({ }^{3} \mathrm{P}\right)+\mathrm{O}\left({ }^{3} \mathrm{P}\right)+\mathrm{M} \rightarrow \mathrm{O}_{2} \text { (precursor) }+\mathrm{M}+5.12 \mathrm{eV}
$$

As was shown in the early 1970s, this exothermic reaction is a source of excitation of the $\mathrm{O}\left({ }^{1} \mathrm{~S}\right)$ atom in the nightglow (for example, in [88]) within the framework of the Barth's mechanism:

$$
\mathrm{O}_{2} \text { (precursor) }+\mathrm{O}\left({ }^{3} \mathrm{P}\right) \rightarrow \mathrm{O}_{2}+\mathrm{O}\left({ }^{1} \mathrm{~S}\right)
$$

However, under the same Barth's mechanism, energy can be transferred to excite singlet or triplet levels of the oxygen molecule, in two ways. Either a one-step channel in reaction (16), or a two-step channel, sequentially (16) and the subsequent energy transfer in the reaction:

$$
\mathrm{O}_{2} \text { (precursor) }+\mathrm{O}_{2} \rightarrow \mathrm{O}_{2}+\mathrm{O}_{2} \text { (electronic state) }
$$

All these proposed energy transfer channels were tested in the course of the beautifully conceived multi-rocket experiment ETON in March 1982. For each of the considered energy transfer channels, corresponding parameterizations were obtained, which have been used up to now [15-17] etc.

In recent years, using data from new rocket experiments, upgraded parameterizations have been proposed for the formation of $\mathrm{O}_{2}\left(\mathrm{~b}^{1} \Sigma_{\mathrm{g}}{ }^{+}, \mathrm{v}=0\right)$ molecules $[18,19]$. Figure 8 shows the contribution of the Barth's mechanism to the formation of the altitude profile of $\mathrm{O}_{2}\left(\mathrm{~b}^{1} \Sigma_{\mathrm{g}}{ }^{+}, \mathrm{v}=0\right)$ concentration in dayglow based on several SABER events and three parameterizations $[15,18,19]$. Unfortunately, the uncertainties of these parameterizations remain too large. But the uncertainty of the atomic oxygen altitude profile above $80 \mathrm{~km}$ can introduce a much larger error, since the efficiency of the Barth's mechanism is proportional to the square of $\mathrm{O}\left({ }^{3} \mathrm{P}\right)$ concentration according to formula (16). Therefore, the selection of test events was motivated by significantly different altitude profiles of atomic oxygen (left panel in Figure 8). While at nightglow this mechanism dominates in the altitude range of 90-103 km, during the daytime its contribution compared to photolysis of $\mathrm{O}_{2}$ and $\mathrm{O}_{3}$ varies from fractions of a percent to 
a few percent according to estimations by $[24,89]$ etc. (compare with our estimations in Figure 8 , right panel). Thus, for daytime conditions, the assessment of the Barth's mechanism contribution to the population of the singlet level of the oxygen molecule is so far only qualitative.
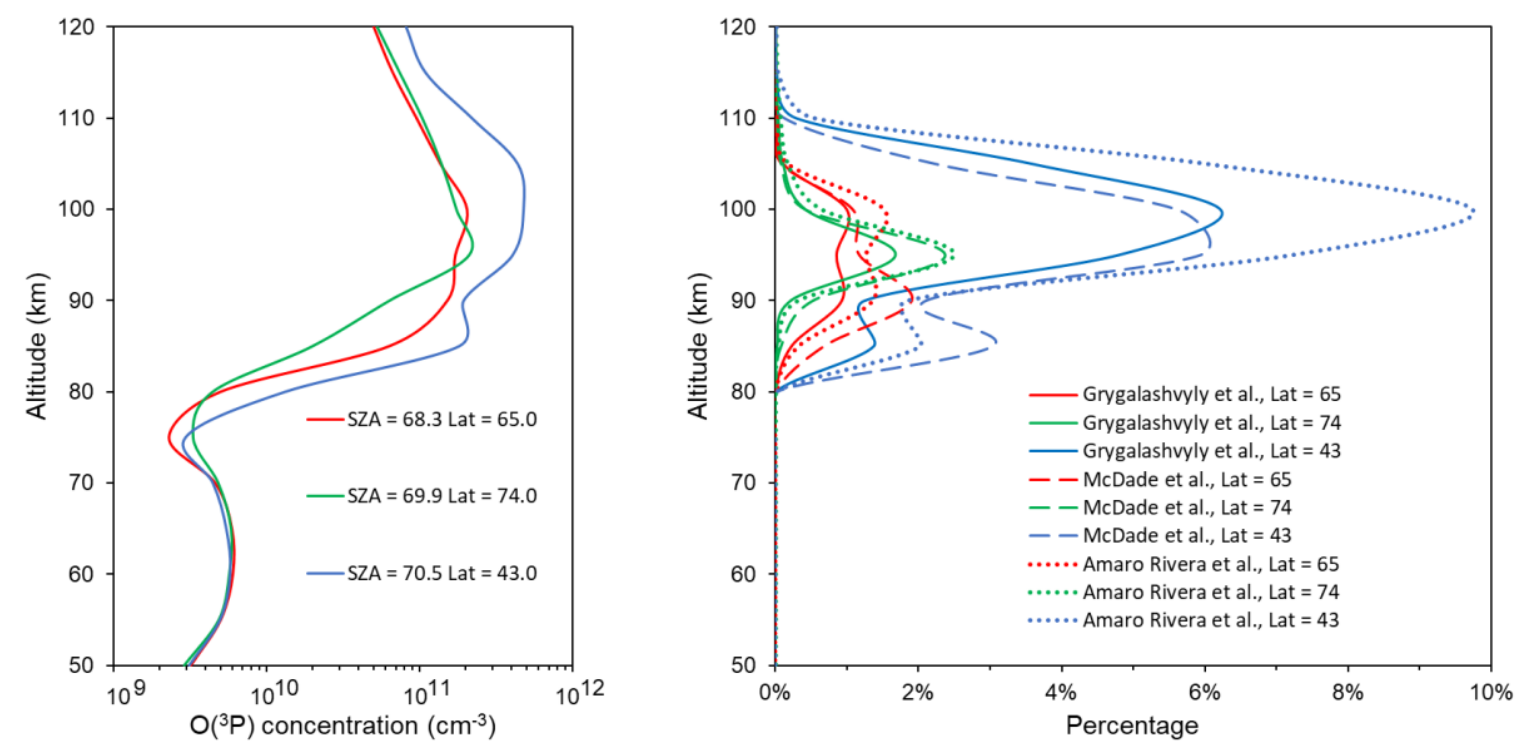

Figure 8. Left panel: altitude profiles of $\mathrm{O}\left({ }^{3} \mathrm{P}\right)$ concentration for different latitudes from TIMED-SABER data (day 172, year 2010). Right panel: the contribution of the Barth' mechanism to the $\mathrm{O}_{2}\left(\mathrm{~b}^{1} \Sigma_{\mathrm{g}}{ }^{+}, \mathrm{v}=0\right)$ excitation with respect to the photolytic excitation mechanism of $\mathrm{O}_{2}\left(\mathrm{~b}^{1} \Sigma_{\mathrm{g}}{ }^{+}, \mathrm{v}=0\right)$ in the framework of YM2011 model. Three sets of parametric coefficients for the Barth' mechanism were used in the calculation (see legend) [15,18,19].

\subsection{Kinetics of $\mathrm{O}_{2}\left(\mathrm{X}^{3} \Sigma^{-}{ }_{\mathrm{g}}, \mathrm{v}\right)$ in $\mathrm{MLT}$}

As mentioned above, in order to calculate the population of the $\mathrm{O}_{2}\left(\mathrm{X}^{3} \Sigma^{-} \mathrm{g}, \mathrm{v}=1\right)$ level, it is necessary to take into account the processes of energy transfer to this level from all overlying excited levels of the oxygen molecule, namely $\mathrm{O}_{2}\left(\mathrm{~b}^{1} \Sigma_{\mathrm{g}}{ }^{+}, \mathrm{v}=0-2\right), \mathrm{O}_{2}\left(\mathrm{a}^{1} \Delta_{\mathrm{g}}, \mathrm{v}=0-5\right), \mathrm{O}_{2}\left(\mathrm{X}^{3} \Sigma^{-} \mathrm{g}, \mathrm{v}=2-35\right)$. To calculate the concentration of $\mathrm{O}_{2}\left(\mathrm{X}^{3} \Sigma^{-} \mathrm{g}, \mathrm{v}=1\right)$, we solved a system of 45 kinetic equations for $\mathrm{O}\left({ }^{1} \mathrm{D}\right)$ and the above-mentioned excited components. A block scheme of this mechanism (Figure 9) was developed by $[33,34]$. In these papers and in $[1,2]$ latest version of database, one can find a database of reaction rate coefficients for the formation and quenching of molecules $\mathrm{O}_{2}\left(\mathrm{X}^{3} \Sigma^{-} \mathrm{g}, \mathrm{v}=1-35\right)$ with corresponding links. We note that in the two most common databases on chemical kinetics and photochemical data, namely, [90] and [60], there are no data on reaction rate coefficients involving electronically-vibrationally excited atmospheric components. 


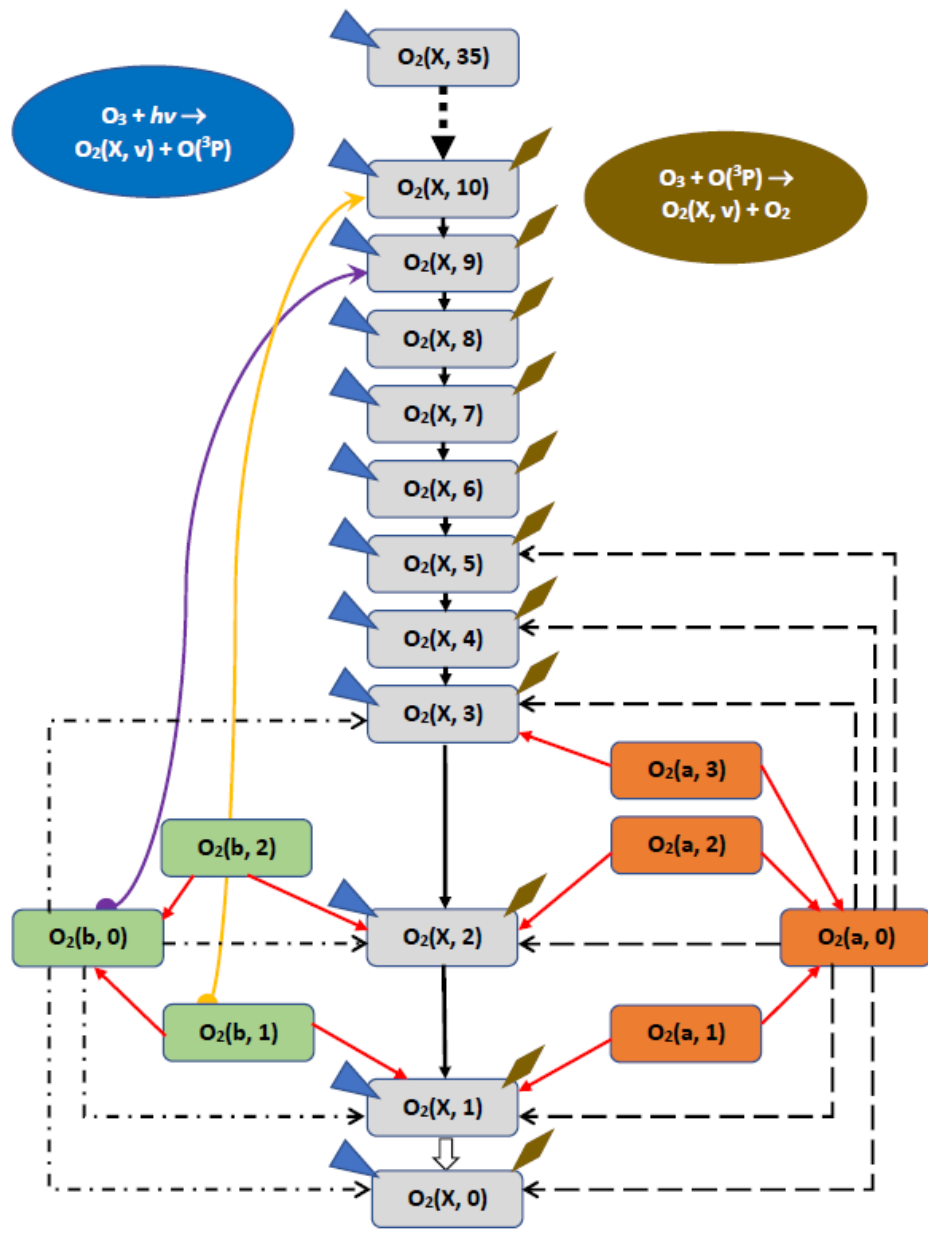

Figure 9. The block-diagram of the population of $\mathrm{O}_{2}\left(X^{3} \Sigma^{-} \mathrm{g}, \mathrm{v}=1-35\right)$ levels in the mesosphere and lower thermosphere, according to YM2011 model (version 2019). A brief notation of levels: $\mathrm{O}_{2}(X, v)=$ $\mathrm{O}_{2}\left(\mathrm{X}^{3} \Sigma^{-} \mathrm{g}, \mathrm{v}\right), \mathrm{O}_{2}(\mathrm{a}, \mathrm{v})=\mathrm{O}_{2}\left(\mathrm{a}^{1} \Delta_{\mathrm{g}}, \mathrm{v}\right), \mathrm{O}_{2}(\mathrm{~b}, \mathrm{v})=\mathrm{O}_{2}\left(\mathrm{~b}^{1} \Sigma_{\mathrm{g}}{ }^{+}, \mathrm{v}\right)$. Direct sources of formation of $\mathrm{O}_{2}(\mathrm{X}, \mathrm{v})$ molecules are photolysis of ozone in the Hartley, Huggins, Chappuis, and Wulf bands (blue triangle), the reaction $\mathrm{O}_{3}+\mathrm{O}\left({ }^{3} \mathrm{P}\right) \rightarrow \mathrm{O}_{2}(\mathrm{X}, \mathrm{v} \leq 30)+\mathrm{O}_{2}$ (brown rhombus). The dashed-dotted line indicates the quasi-resonant $E^{\prime}$ ' energy transfer as a result of $\mathrm{O}_{2}(\mathrm{~b}, 0)+\mathrm{O}_{2} \rightarrow \mathrm{O}_{2}(\mathrm{a}, \mathrm{v})+\mathrm{O}_{2}(\mathrm{X}, 3-\mathrm{v})$; long-dashed lines denote quasi-resonant EV energy transfer as a result of $\mathrm{O}_{2}(\mathrm{a}, 0)+\mathrm{O}_{2} \rightarrow \mathrm{O}_{2}(\mathrm{X}, \mathrm{v})+\mathrm{O}_{2}(\mathrm{X}, 5-\mathrm{v})$; red inclined lines-quasi-resonant EV exchange as a result of $\mathrm{O}_{2}(\mathrm{a}, \mathrm{v})+\mathrm{O}_{2} \rightarrow \mathrm{O}_{2}(\mathrm{X}, \mathrm{v})+\mathrm{O}_{2}(\mathrm{a}, 0)$ and $\mathrm{O}_{2}(\mathrm{~b}, \mathrm{v})+\mathrm{O}_{2} \rightarrow \mathrm{O}_{2}(\mathrm{X}, \mathrm{v})+\mathrm{O}_{2}(\mathrm{~b}, 0)$ for the first and second singlet states of the oxygen molecule. The black vertical arrows are the relaxation processes of the $\mathrm{O}_{2}(X, v)$ levels in the reactions $\mathrm{O}_{2}(X, v)+\mathrm{O}_{2}$ $\rightarrow \mathrm{O}_{2}(\mathrm{X}, \mathrm{v}-1)+\mathrm{O}_{2}(\mathrm{X}, 1), \mathrm{O}_{2}(\mathrm{X}, \mathrm{v})+\mathrm{O}_{2} \rightarrow \mathrm{O}_{2}(\mathrm{X}, \mathrm{v}-1)+\mathrm{O}_{2}(\mathrm{X}, 0), \mathrm{O}_{2}(\mathrm{X}, \mathrm{v})+\mathrm{O}\left({ }^{3} \mathrm{P}\right) \rightarrow \mathrm{O}_{2}(\mathrm{X}, \mathrm{v}-\Delta \mathrm{v})+$ $\mathrm{O}\left({ }^{3} \mathrm{P}\right)$ and $\mathrm{O}_{2}(X, v)+\mathrm{N}_{2} \rightarrow \mathrm{O}_{2}(X, v-2)+\mathrm{N}_{2}(X, 1)$. The wide non-solid arrow for $\mathrm{O}_{2}(X, 1)$ denotes VT quenching of $\mathrm{O}_{2}(X, 1)+\mathrm{M} \rightarrow \mathrm{O}_{2}(X, 0)+\mathrm{M}$, where $\mathrm{M}=\mathrm{O}_{2}, \mathrm{~N}_{2}, \mathrm{O}\left({ }^{3} \mathrm{P}\right)$. The quasi-resonant reactions that we hypothesized are indicated by curved lines: violet is for the reaction $\mathrm{O}_{2}(b, 0)+\mathrm{N}_{2} \rightarrow \mathrm{O}_{2}(X, 9)+$ $\mathrm{N}_{2}$, yellow is for the reaction $\mathrm{O}_{2}(\mathrm{~b}, 1)+\mathrm{O}\left({ }^{3} \mathrm{P}\right) \rightarrow \mathrm{O}_{2}(\mathrm{X}, 10)+\mathrm{O}\left({ }^{3} \mathrm{P}\right)$ (see Table 2 ).

Key feature of the model shown in Figure 9 is that to populate the lowest level of $\mathrm{O}_{2}\left(\mathrm{X}^{3} \Sigma_{\mathrm{g}}^{-}, \mathrm{v}=1\right)$, it is necessary to consider the five main channels of vibrational excitation for the three lower electronic levels of the oxygen molecule:

(1) Direct population of $\mathrm{O}_{2}\left(\mathrm{X}^{3} \Sigma^{-} \mathrm{g}, \mathrm{v}=1-35\right)$ as a result of ozone photolysis (in the triplet channel) in the Hartley, Huggins, Chappuis, and Wulf bands. Moreover, the photodissociation rate substantially depends on the wavelength of solar radiation, as can be seen from Figure 2. The methodology for calculating rates of the photodissociation processes which sequentially takes 
into account threshold values of the excitation for each vibrational level is described in detail in $[33,46]$.

(2) Direct simultaneous population of $\mathrm{O}_{2}\left(\mathrm{X}^{3} \Sigma^{-}{ }_{\mathrm{g}}, \mathrm{v}=1-30\right)$ in the reaction $\mathrm{O}_{3}+\mathrm{O}\left({ }^{3} \mathrm{P}\right) \rightarrow \mathrm{O}_{2}\left(\mathrm{X}^{3} \Sigma_{\mathrm{g}}^{-}\right.$, $\mathrm{v}=0-30)+\mathrm{O}_{2}$ whose rate coefficient is highly dependent on kinetic temperature [60,91].

(3) Cascade population of each $\mathrm{O}_{2}\left(\mathrm{X}^{3} \Sigma^{-} \mathrm{g}, \mathrm{v}\right)$ level due to transitions from all overlying (with respect to it) levels as a result of reaction (14). The rate coefficients of all cascade transitions were calculated by [62] and visualized by us in Figure 6 . The term which takes into account the contribution of mentioned cascade transitions in the kinetic equation for $\mathrm{O}_{2}\left(\mathrm{X}^{3} \Sigma^{-} \mathrm{g}, \mathrm{v}\right)$ is

$$
\text { Production }\left(\mathrm{O}_{2}\left(X^{3} \Sigma_{g}^{-}, v\right)\right)=\left[O\left({ }^{3} P\right)\right] \cdot \sum_{m=v+1}^{30}\left[O_{2}\left(X^{3} \Sigma_{g}^{-}, m\right)\right] \cdot k\left(O_{2}(X, m) ; O\left({ }^{3} P\right)\right)
$$

Thus, we have to consider 464 cascade transitions to describe the population of the $\mathrm{O}_{2}\left(\mathrm{X}^{3} \Sigma^{-} \mathrm{g}\right.$, $\mathrm{v}=1$ ) level only.

(4) Energy transfer from $\mathrm{O}_{2}\left(\mathrm{~b}^{1} \Sigma^{+} \mathrm{g}, \mathrm{v} \leq 2\right)$ and $\mathrm{O}_{2}\left(\mathrm{a}^{1} \Delta_{\mathrm{g}}, \mathrm{v} \leq 5\right)$ levels as a result of fast reactions (9), (10).

(5) The processes of $(\mathrm{V}-\mathrm{V})$ and $(\mathrm{V}-\mathrm{T})$ vibrational relaxation in collisions with $\mathrm{O}_{2}$ and $\mathrm{N}_{2}$ (see Section 2.2).

The channels (2-5) continue to be the most effective in the $\mathrm{O}_{2}\left(\mathrm{X}^{3} \Sigma^{-} \mathrm{g}, \mathrm{v}=1-30\right)$ kinetics in nighttime mesosphere, however, this problem has not yet been solved by anyone.

The algorithm proposed in Figure 9 allows one to calculate the daytime distribution of $\mathrm{O}_{2}\left(\mathrm{X}^{3} \Sigma^{-}{ }_{\mathrm{g}}\right.$ $\mathrm{v}=1-35$ ) molecules in the altitude range of $50-120 \mathrm{~km}$ (an example of calculation for $\mathrm{v}=1-35$ is shown in Figure 10) depending on the date, latitude, and zenith angle of the sun.

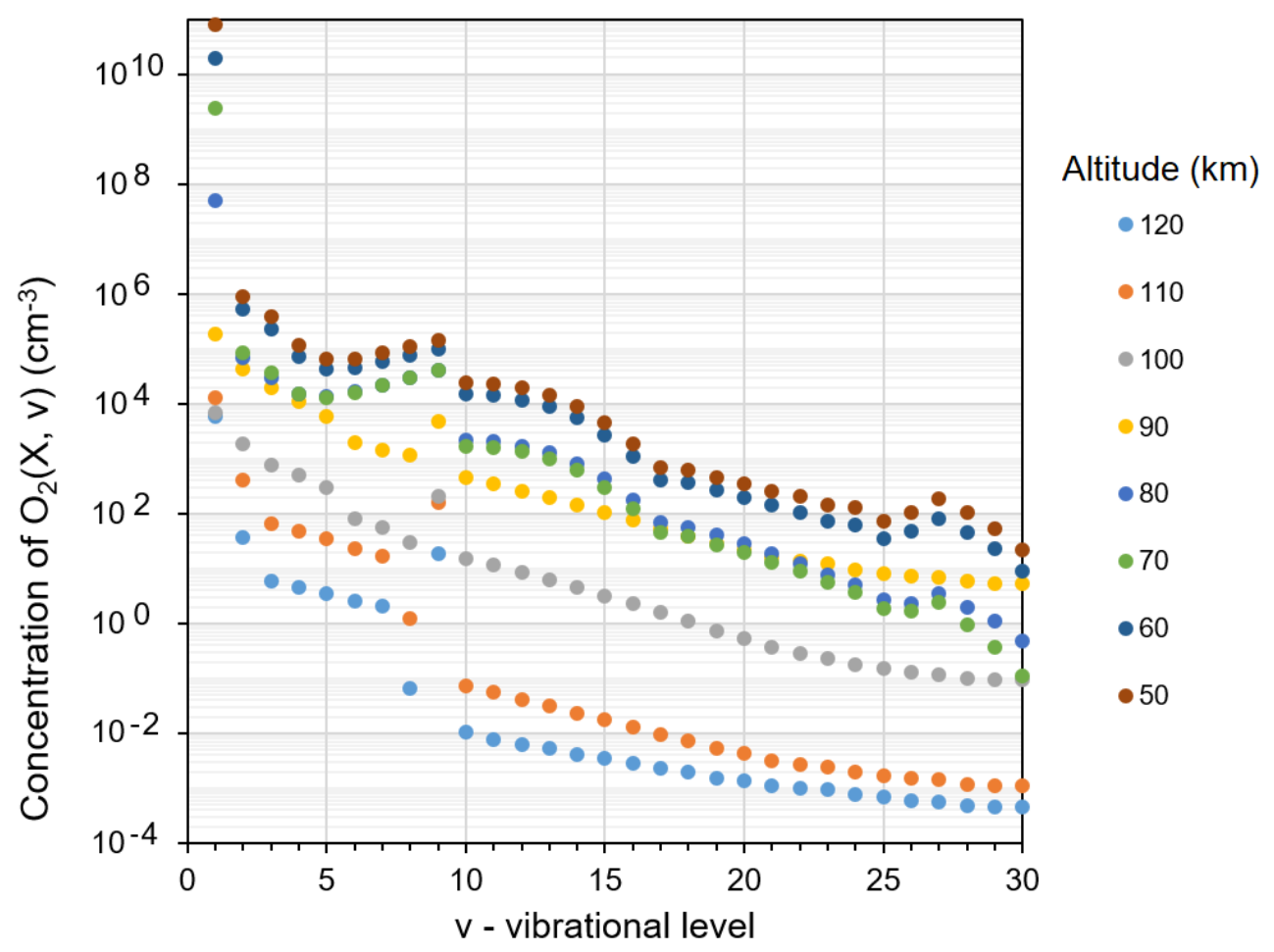

Figure 10. Population of $\mathrm{O}_{2}\left(\mathrm{X}^{3} \Sigma^{-} \mathrm{g}, \mathrm{v}=1-35\right)$ levels for altitude from 50 to $120 \mathrm{~km}$. Calculation using YM2011 model for TIMED-SABER event (37_01468), Date 16.03.2002, Lat = 43.3, SZA = 50.0.

Figure 11 gives an example of calculating the altitude profiles of the concentrations of $\mathrm{O}_{2}\left(\mathrm{X}^{3} \Sigma^{-} \mathrm{g}\right.$, $\mathrm{v}=1)$ and $\mathrm{O}_{2}\left(\mathrm{X}^{3} \Sigma^{-} \mathrm{g}, \mathrm{v}=2\right)$ for different solar zenith angle (SZA) during one day (based on the TIMED-SABER data [92] on the atmospheric composition and SORCE data [93] on the spectral 
characteristics of solar radiation in the range $120-900 \mathrm{~nm}$ ). A characteristic feature of these altitude profiles is the low variability of these profiles during daylight hours, at least for SZA $\leq 85$. In addition, it is necessary to pay attention to the abnormally high concentration of $\mathrm{O}_{2}\left(\mathrm{X}^{3} \Sigma^{-} \mathrm{g}, \mathrm{v}=2\right)$ molecules in the altitude range $90-100 \mathrm{~km}$ (the threshold of excitation of this level of the oxygen molecule is $3089 \mathrm{~cm}^{-1}$ ).

To simulate the altitude profile of $\mathrm{O}_{2}\left(\mathrm{X}^{3} \Sigma^{-} \mathrm{g}, \mathrm{v}=1\right)$ concentration in various geophysical situations, we used a set of standard atmospheric models TROP (TROPics), SAS (SubArctic Summer), MLW (Middle-Latitude Winter), MLS (Middle-Latitude Summer), as well as fifty SABER events for summer equinox. We presented all these profiles as functions of atmospheric pressure (Figure 4, from [34]). It was possible to obtain a universal altitude profile of the resulting quantum output (RQO) of the production of $\mathrm{O}_{2}\left(\mathrm{X}^{3} \Sigma^{-} \mathrm{g}, \mathrm{v}=1\right)$ molecules per act of ozone photolysis in the Hartley, Huggins, Chappuis, and Wulf bands for the altitude range of $50-90 \mathrm{~km}$ depending on atmospheric pressure. It turned out that the shape of the altitude distribution of RQO weakly depends on the date, latitude and SZA [34].

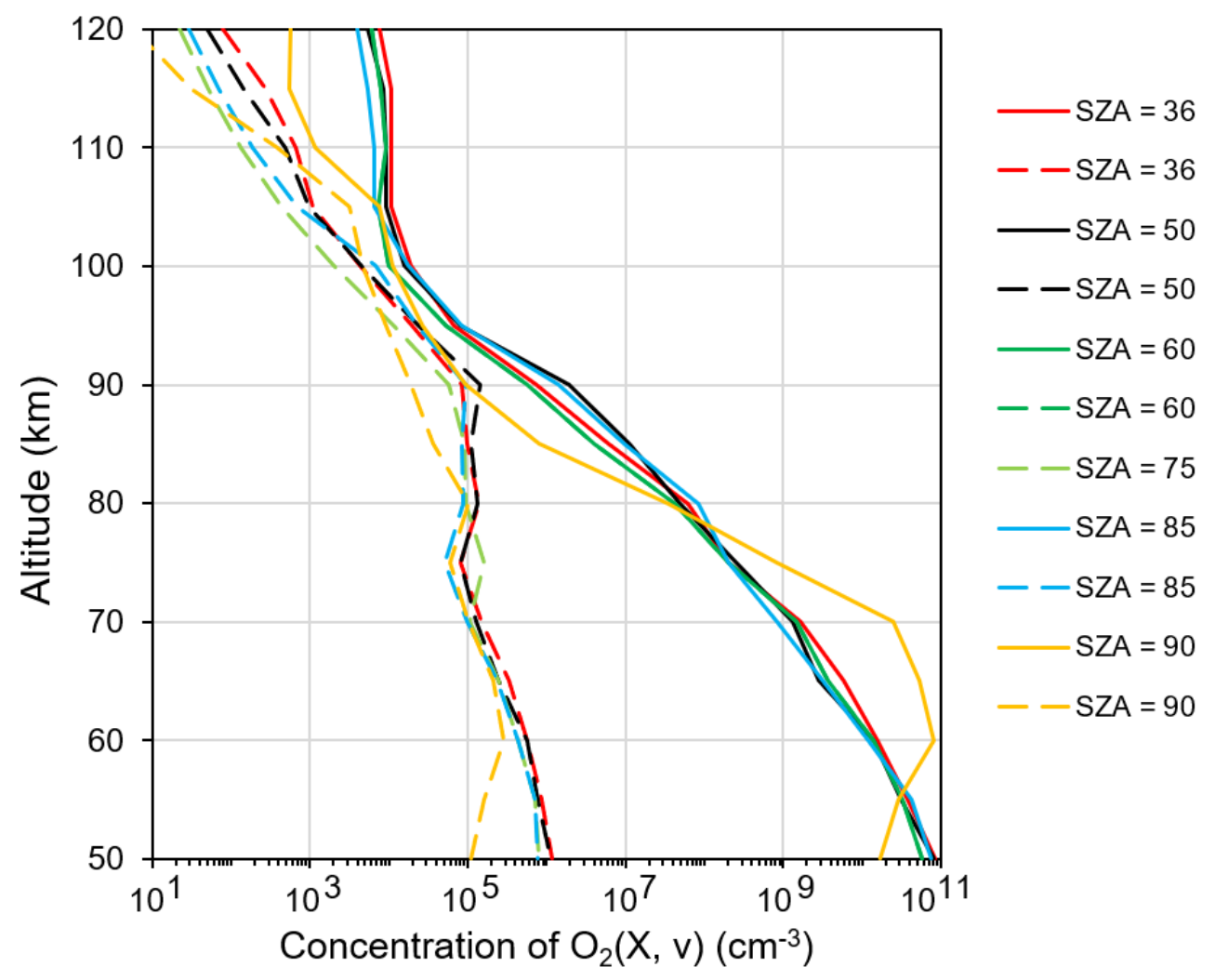

Figure 11. Altitude distributions of $\mathrm{O}_{2}\left(X^{3} \Sigma^{-} \mathrm{g}, \mathrm{v}=1\right)$ (solid curve) and $\mathrm{O}_{2}\left(\mathrm{X}^{3} \Sigma^{-} \mathrm{g}, \mathrm{v}=2\right)$ (dashed curve) depending on solar zenith angle. Calculation is for SABER events during the vernal equinox 2002 using YM2011 model.

\section{Kinetics of $\mathrm{O}_{2}$ and $\mathrm{O}_{3}$ Photolysis Products in MLT. The Modern Model}

All processes considered in Section 2 were taken into account in the kinetics model of $\mathrm{O}_{2}$ and $\mathrm{O}_{3}$ products. The first publication of the model was in 2003 [30], the first full-functional version of the model was published in 2006 [32], the upgrade version YM2011 (Figure 12) was presented in publications 2011-2019. In the framework of the YM2011 model, the concentrations of the molecules $\mathrm{O}_{2}\left(\mathrm{X}^{3} \Sigma_{\mathrm{g}}{ }^{-}, \mathrm{v}=1-35\right), \mathrm{O}_{2}\left(\mathrm{a}^{1} \Delta_{\mathrm{g}}, \mathrm{v}=0-5\right), \mathrm{O}_{2}\left(\mathrm{~b}^{1} \Sigma_{\mathrm{g}}{ }^{+}, \mathrm{v}=0-2\right)$ are calculated from the solution of the system of kinetic equations for these excited levels. The system of kinetic equations can be solved analytically, considering the hierarchical location of the excited levels as a function of energy. 


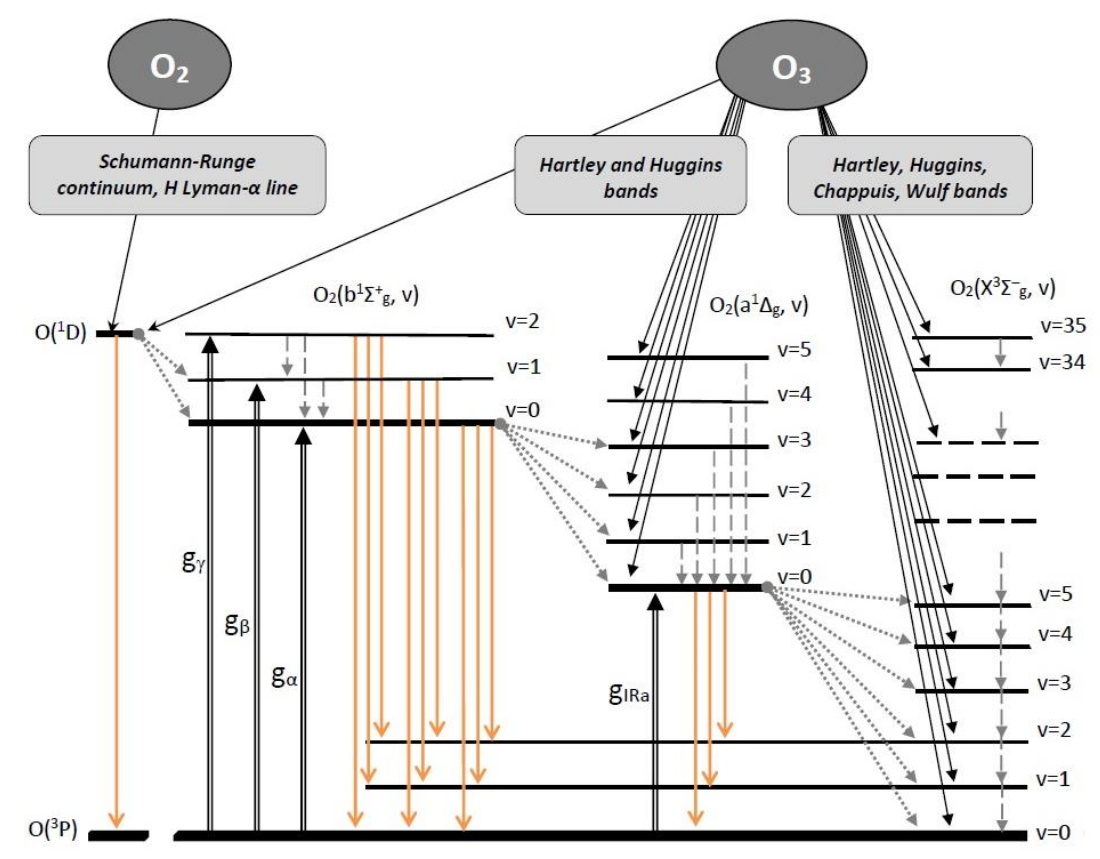

Figure 12. The scheme of electronic-vibrational kinetics of the products of $\mathrm{O}_{2}$ and $\mathrm{O}_{3}$ photolysis in the MLT region (YM2011 model, version 2019), taking into account 9 excited levels of the oxygen molecule (three levels $\mathrm{O}_{2}\left(\mathrm{~b}^{1} \Sigma^{+} \mathrm{g}, \mathrm{v}=0,1,2\right)$, six levels $\left.\mathrm{O}_{2}\left(\mathrm{a}^{1} \Delta_{\mathrm{g}}, \mathrm{v}=0-5\right)\right)$, 35 levels $\mathrm{O}_{2}\left(\mathrm{X}^{3} \Sigma^{-} \mathrm{g}, \mathrm{v}=1-35\right)$ and, also, the excited level of the oxygen atom, $\mathrm{O}\left({ }^{1} \mathrm{D}\right)$. Solid thin lines with arrows designate the processes of $\mathrm{O}_{2}$ and $\mathrm{O}_{3}$ photolysis. Double vertical lines with arrows designate the processes of solar radiation resonance absorption in the $762 \mathrm{~nm}\left(\mathrm{~g}_{\alpha}\right), 688 \mathrm{~nm}\left(\mathrm{~g}_{\beta}\right), 629 \mathrm{~nm}\left(\mathrm{~g}_{\gamma}\right)$ and in the $1.27 \mu \mathrm{m}\left(\mathrm{g}_{\text {IRa }}\right)$ bands. Short dashed inclined lines with arrows present energy transfer from $\mathrm{O}\left({ }^{1} \mathrm{D}\right)$ to the $\mathrm{O}_{2}\left(\mathrm{~b}^{1} \Sigma^{+} \mathrm{g}\right.$, $\mathrm{v}=0,1)$, from $\mathrm{O}_{2}\left(\mathrm{~b}^{1} \Sigma^{+} \mathrm{g}, \mathrm{v}=0\right)$ to $\mathrm{O}_{2}\left(\mathrm{a}^{1} \Delta_{\mathrm{g}}, \mathrm{v}=0-3\right)$ and from $\mathrm{O}_{2}\left(\mathrm{a}^{1} \Delta_{\mathrm{g}}, \mathrm{v}=0\right)$ to $\mathrm{O}_{2}\left(\mathrm{X}^{3} \Sigma_{\mathrm{g}}^{-}, \mathrm{v}=0-5\right)$ at collisional quenching. Long dashed vertical lines with arrows denote collisional $\mathrm{V}-\mathrm{V}$ transitions. Solid orange vertical lines with arrows pointed down designate the processes of emissions from electronic-vibrational levels of $\mathrm{O}_{2}$ molecule and from excited atom $\mathrm{O}\left({ }^{1} \mathrm{D}\right)$.

In the formation of altitude distributions of the vibrational level populations of the oxygen molecule in the ground electronic state $\mathrm{O}_{2}\left(\mathrm{X}^{3} \Sigma_{\mathrm{g}}{ }^{-}, \mathrm{v}=1-35\right)$ we took into account not only the direct excitation channel, namely, ozone photolysis in the Hartley, Huggins, Chappuis, and Wulf (200-900 nm) bands, but also transfer of energy from excited levels of $\mathrm{O}_{2}\left(\mathrm{a}^{1} \Delta_{\mathrm{g}}, \mathrm{v}=0-5\right)$ and $\mathrm{O}_{2}\left(\mathrm{~b}^{1} \Sigma_{\mathrm{g}}{ }^{+}, \mathrm{v}=0,1,2\right)$ which are populated both as a result of ozone photolysis in the Hartley band, and as due to energy transfer from the excited oxygen atom $\mathrm{O}\left({ }^{1} \mathrm{D}\right)$.

In the new version of the YM2011 model (Figure 12), we first took into account the additional channels for the formation of $\mathrm{O}\left({ }^{1} \mathrm{D}\right)$ atoms during the photolysis of ozone in the Huggins band, as well as the energy transfer from $\mathrm{O}_{2}\left(\mathrm{~b}^{1} \Sigma^{+} \mathrm{g}, \mathrm{v}=0,1\right)$ to $\mathrm{O}_{2}\left(\mathrm{X}^{3} \Sigma^{-} \mathrm{g}, \mathrm{v}=9\right.$ and 10$)$.

The YM2011 model is self-consistent and allows you to solve both forward and inverse problems. By the forward problem, we mean the calculation of altitude profiles of concentration of excited oxygen components in the MLT region. Bear in mind that the concentration of molecules in the excited state is related with volume emission rate (VER) through the Einstein coefficient (Section 2.3). Thus, in the framework of the YM2011 model, for different atmospheric conditions (season, latitude, zenith angle of the sun, etc.) the altitude distributions of volume emission rates can be calculated not only for traditional oxygen bands of $\mathrm{O}_{2} \operatorname{IR} \operatorname{Atm}(0,0)$ at $1.27 \mu \mathrm{m}$ and $\mathrm{O}_{2} \operatorname{Atm}(0,0)$ at $0.762 \mu \mathrm{m}$, but also for the systems of $\mathrm{O}_{2}$ atmospheric, IR atmospheric, and Noxon bands (Section 2.3). The calculation results of the forward problem can be compared with the experimentally measured altitude profiles of the excited oxygen components. This allowed us to validate the model (Section 4.1). By the inverse photochemical problem, we understand the retrieval of concentrations of non-radiating small atmospheric components that are in the main unexcited state (for example, $\mathrm{O}\left({ }^{3} \mathrm{P}\right), \mathrm{O}_{3}, \mathrm{CO}_{2}$ ) based on the observation of altitude 
profiles of the emitting singlet levels of oxygen atoms and molecules. In the inverse problem, these excited levels manifest themselves as proxies for the retrieving of $\mathrm{O}\left({ }^{3} \mathrm{P}\right), \mathrm{O}_{3}, \mathrm{CO}_{2}$ concentrations.

In addition, the YM2011 model allows us to estimate the uncertainty of the calculated concentrations of excited and unexcited components depending on the altitude based on the sensitivity analysis of the model with respect to all its parameters $[1,2,35]$. Next, we will present some results of solving the forward and inverse problems in frameworks of the YM2011 model, using the sensitivity analysis of the model and estimating the uncertainties of the results using the Monte Carlo method.

\section{Applications}

\subsection{Forward Problem}

Validation of the YM2011 model has been carried out by Yankovsky and Manuilova [32] who compared measured values of the concentration of excited $\mathrm{O}_{2}\left(\mathrm{~b}^{1} \Sigma_{\mathrm{g}}{ }^{+}, \mathrm{v}=0\right)$ and $\mathrm{O}_{2}\left(\mathrm{a}^{1} \Delta_{\mathrm{g}}, \mathrm{v}=0\right)$ molecules according to the METEORS experiment [27] with values calculated in the framework of the YM2011 model and showed that the model sufficiently describes the altitude profiles of excited oxygen components.

It is also possible to solve the forward problem in the framework of the YM2011 model based on TIMED-SABER satellite experiment data. For each event (with an interval of about $50 \mathrm{~s}$ ), in this experiment there are data about the altitude distribution of the main atmospheric unexcited components, the kinetic temperature of the gas, as well as the concentrations of excited $\mathrm{O}\left({ }^{1} \mathrm{D}\right)$ atoms and $\mathrm{O}_{2}\left(\mathrm{a}^{1} \Delta_{\mathrm{g}}, \mathrm{v}=0\right)$ molecules with a vertical resolution $\sim 1 \mathrm{~km}$. Based on TIMED-SABER data for the four days in 2010 year (the autumn and vernal equinoxes, summer and winter solstices) and the solar radiation spectrum (in the wavelength range 120-900 $\mathrm{nm}$ ) from SORCE satellite data synchronized with these events, we calculated the altitude profiles of the $\mathrm{O}\left({ }^{1} \mathrm{D}\right)$ and $\mathrm{O}_{2}\left(\mathrm{~b}^{1} \Sigma_{\mathrm{g}}{ }^{+}, \mathrm{v}=0-2\right)$ concentrations in the framework of the YM2011 model (Figure 13). The simulation results for $\mathrm{O}\left({ }^{1} \mathrm{D}\right)$ concentration almost coincided with the data presented on the SABER website (version 1.07) below $105 \mathrm{~km}$. More detailed description of the forward problem solution in the framework of the YM2011 model can be found in $[1,2,32]$.
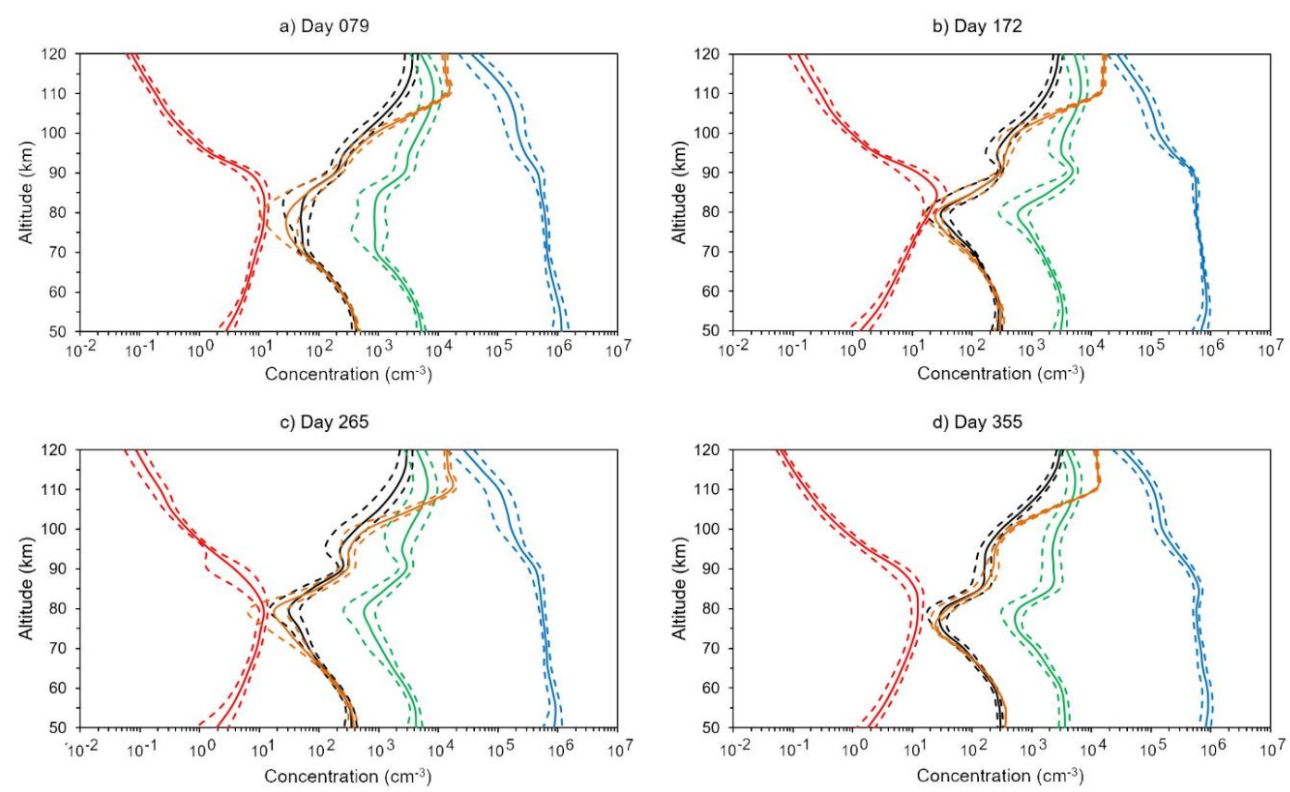

Figure 13. Daily mean altitude profiles of $\mathrm{O}_{2}\left(\mathrm{~b}^{1} \Sigma_{\mathrm{g}}{ }^{+}, \mathrm{v}=0\right.$ ) (blue solid line), $\mathrm{O}_{2}\left(\mathrm{~b}^{1} \Sigma_{\mathrm{g}}{ }^{+}, \mathrm{v}=1\right.$ ) (green solid line), $\mathrm{O}_{2}\left(\mathrm{~b}^{1} \Sigma_{\mathrm{g}}{ }^{+}, \mathrm{v}=2\right.$ ) (red solid line), $\mathrm{O}\left({ }^{1} \mathrm{D}\right)$ (black solid line) and their standard deviations (dashed lines) calculated via YM2011 based on TIMED-SABER data for 4 days in 2010: (a) day 79, (b) day 172, (c) day 265, (d) day 355. Orange lines represent altitude profiles of $O\left({ }^{1} \mathrm{D}\right)$ according to TIMED-SABER data. 


\subsection{Inverse Problem}

Since the YM2011 model sufficiently reproduces the altitude distribution of excited oxygen components, it is possible to use this model to solve inverse problems of retrieving altitude profiles of concentration of non-radiating small atmospheric components. A typical example of the inverse problem is the retrieval of the altitude profile of ozone concentration using observations of the volume emission rate of $\mathrm{O}_{2} \mathrm{IR}$ atmospheric band at a wavelength of $1.27 \mu \mathrm{m}$. Solving this problem in the framework of the MSZ model, Smith et al. [26] found the systematic overestimation of the retrieved ozone concentration. The YM2011 model can explain this result. The reason is that the MSZ model does not take into account the cascade population of $\mathrm{O}_{2}\left(\mathrm{a}^{1} \Delta_{\mathrm{g}}, \mathrm{v}=0\right)$ level from overlying electronically-vibrationally excited levels of $\mathrm{O}_{2}\left(\mathrm{a}^{1} \Delta_{\mathrm{g}}, \mathrm{v}>0\right)$ which, in turn, are populated not only as a result of ozone photolysis but also due to photo processes involving $\mathrm{O}_{2}$ molecules [47].

A detailed analysis of the population and quenching processes of electronically-vibrationally excited $\mathrm{O}_{2}$ molecules in the MLT region using sensitivity analysis has been performed by Yankovsky et al. [1] and Yankovsky and Manuilova [35] which showed that the altitude profiles of each of these levels individually depend on the main atmospheric components such as ozone, atomic oxygen, and carbon dioxide. These relations allowed us to develop new techniques (methods) for retrieving altitude profiles of $\mathrm{O}_{3}, \mathrm{O}\left({ }^{3} \mathrm{P}\right)$ and $\mathrm{CO}_{2}$ concentrations using $\mathrm{O}_{2}\left(\mathrm{~b}^{1} \Sigma^{+}{ }_{\mathrm{g}}, \mathrm{v}=0-2\right)$ and $\mathrm{O}\left({ }^{1} \mathrm{D}\right)$ as a proxy. A detailed description of above-mentioned techniques can be found in $[1,2,35]$ together with the analytical formulas for retrieving the altitude profiles of $\mathrm{O}_{3}, \mathrm{O}\left({ }^{3} \mathrm{P}\right)$ and $\mathrm{CO}_{2}$.

An important step in solving both the forward and inverse problems is to estimate the uncertainty of the solution. Note that sensitivity analysis can be used not only to establish relationships between model parameters, but also to estimate the uncertainty of a solution with known parameter errors. Uncertainty estimations of both forward and inverse problems (on the example of ozone and atomic oxygen altitude profiles retrieval) are presented in [1]. Another method for estimating uncertainty is the Monte Carlo method. In [2], a detailed description of the Monte Carlo method application to photochemical modelling is presented in addition to estimates of uncertainties for $\mathrm{O}_{3}, \mathrm{O}\left({ }^{3} \mathrm{P}\right)$ and $\mathrm{CO}_{2}$ retrieved in the MLT in the framework of the YM2011 model.

\section{Conclusions}

(a) The study presents contemporary insights to the daytime oxygen emissions in the mesopause region and above. We consider this altitude region, since in the mesosphere and lower thermosphere, intense energy transfer occurs between electronically vibrationally excited singlet levels of the oxygen molecule. In Section 2.2, we showed that a significant part of these reactions has high rates due to quasi-resonant effects during energy transfer.

(b) Above the mesopause, special attention should be given to both the profile of atomic oxygen itself and to processes with its participation, since rate coefficients of reactions involving $\mathrm{O}\left({ }^{3} \mathrm{P}\right)$ have the greatest error today. Below the mesopause region where the role of atomic oxygen is insignificant, considering the electronic-vibrational kinetics of the $\mathrm{O}_{2}$ and $\mathrm{O}_{3}$ photolysis products solves the issues of the MSZ model associated with an overstatement of the retrieved ozone concentration in the mesosphere (see Introduction).

(c) In the presented new version of the YM2011 model, we first considered the additional channels for the formation of $\mathrm{O}\left({ }^{1} \mathrm{D}\right)$ atoms during the photolysis of ozone in the Huggins band, as well as the energy transfer from $\mathrm{O}_{2}\left(\mathrm{~b}^{1} \Sigma^{+} \mathrm{g}, \mathrm{v}=0,1\right)$ to $\mathrm{O}_{2}\left(\mathrm{X}^{3} \Sigma^{-} \mathrm{g}, \mathrm{v}=9\right.$ and 10). Taking into account the energy transfer from vibrationally excited singlet levels of $\mathrm{O}_{2}$ molecule to vibrationally excited levels of the ground electronic state allows us to construct a complete model of the altitude distribution of $\mathrm{O}_{2}\left(\mathrm{X}^{3} \Sigma_{\mathrm{g}}{ }^{-}, \mathrm{v}=1-35\right)$ in the MLT region (Section 2.5). Currently, there is only one kinetics model of photolysis products that considers an energy transfer between 44 electronically-vibrationally excited levels of molecular oxygen and excited oxygen atom, includes collected for many years 
database of reaction rate coefficients and recently calculated Einstein coefficients, namely, the YM2011 model.

(d) Special attention is given to the association of oxygen atoms in the triple reaction (Section 2.4) It has been shown that for different sets of fitting coefficients its contribution to $\mathrm{O}_{2}\left(\mathrm{~b}^{1} \Sigma^{+}{ }_{\mathrm{g}}, \mathrm{v}\right)$ and $\mathrm{O}_{2}\left(\mathrm{a}^{1} \Delta_{\mathrm{g}}, \mathrm{v}\right)$ population is neglectable in daytime conditions.

(e) For the first time, new estimates of the radiative lifetimes of electronically-vibrationally excited oxygen molecules $\mathrm{O}_{2}\left(\mathrm{~b}^{1} \Sigma^{+}{ }_{\mathrm{g}}, \mathrm{v}=0-10\right)$ are presented. These estimates are relevant due to the fact that in the thermosphere, as the height increases, the role of radiation quenching becomes dominant compared to the collisional deactivation (see Section 2.3).

(f) The model YM2011 allows us to solve both forward and inverse problems. By the forward problem, we mean the calculation of altitude profiles of concentration of excited oxygen components in the MLT region (see Section 4.1). This is especially important for those components whose observations have not yet been implemented. By the inverse photochemical problem, we understand the retrieval of concentrations of non-radiating small atmospheric components that are in the main unexcited state (for example, $\mathrm{O}\left({ }^{3} \mathrm{P}\right), \mathrm{O}_{3}, \mathrm{CO}_{2}$ ) based on the observation of altitude profiles of the emitting singlet levels of oxygen atoms and molecules (see Section 4.2).

The model is continuously developing and enriching itself with new data and fields of application. Currently, the YM2011 model is included in a number of algorithms (GRANADA and ALI-ARMS) and is used for calculations [94]. In the near future, the authors plan to solve the problem of expanding the application of the model for twilight conditions.

Author Contributions: V.Y. proposed the idea of the study. Methodology, software, validation, and manuscript preparation are joint efforts of V.Y. and E.V. All authors have read and agreed to the published version of the manuscript.

Funding: This work was partially funded by the Russian Fund for Basic Research (grant RFBR No.20-05-00450).

Acknowledgments: Authors dedicate this manuscript to the memory of Tom Slanger who has been interested in this model since 1999. Discussions and selfless support of colleagues were very important for the development of the YM2011 model. Thanks to Lubov Yankovskaya and Gustav Shved for the attentive and friendly attitude to our work. Authors thank the following people who contributed to the development and testing of the model: Rada Manuilova, Artem Feofilov, Fabrizio Esposito, Veronika Kuleshova, Alexey Semenov, Aleksander Babaev, Kseniia Martyshenko, Ekaterina Fedotova, Anatoly Semenov, Georg Witt, Mykhaylo Grygalashvyly, and many other colleagues. Also, authors are thankful to the editor and anonymous reviewers for valuable suggestions and comments.

Conflicts of Interest: The authors declare no conflict of interest.

\section{References}

1. Yankovsky, V.A.; Martyshenko, K.V.; Manuilova, R.O.; Feofilov, A.G. Oxygen dayglow emissions as proxies for atomic oxygen and ozone in the mesosphere and lower thermosphere. J. Mol. Spectrosc. 2016, 327, 209-232. [CrossRef]

2. Yankovsky, V.; Vorobeva, E.; Manuilova, R. New techniques for retrieving the $\left[\mathrm{O}\left({ }^{3} \mathrm{P}\right)\right],\left[\mathrm{O}_{3}\right]$ and $\left[\mathrm{CO}_{2}\right]$ altitude profiles from dayglow oxygen emissions: Uncertainty analysis by the Monte Carlo method. Adv. Space Res. 2019, 64, 1948-1967. [CrossRef]

3. Degen, V. Nightglow emission rates in the $\mathrm{O}_{2}$ Herzberg bands. J. Geophys. Res. 1977, 82, $2437-2438$. [CrossRef]

4. Llewellyn, E.J.; Solheim, B.H. The excitation of the infrared atmospheric oxygen bands in the nightglow. Planet. Space Sci. 1978, 26, 533-538. [CrossRef]

5. Klais, O.; Laufer, A.H.; Kurylo, M.J. Atmospheric quenching of vibrationally excited $\mathrm{O}_{2}\left(\mathrm{a}^{1} \Delta_{\mathrm{g}}, \mathrm{v}\right)$. J. Chem. Phys. 1980, 73, 2696-2699. [CrossRef]

6. Greer, R.G.H.; Llewellyn, E.J.; Solheim, B.H.; Witt, G. The excitation of the $\mathrm{O}_{2}\left(\mathrm{~b}^{1} \Sigma_{\mathrm{g}}{ }^{+}\right)$in the nightglow. Planet. Space Sci. 1981, 29, 383-389. [CrossRef]

7. Harris, R.D.; Adams, G.W. Where does the O(1D) energy go? J. Geophys. Res. 1983, 88, 4918-4928. [CrossRef] 
8. Thomas, R.J.; Young, R.A. Measurement of atomic oxygen and related airglows in the lower thermosphere. J. Geophys. Res. 1981, 86, 7389-7393. [CrossRef]

9. Shimazaki, T. The photochemical time constants of minor constituents and their families in the middle atmosphere. J. Atmos. Terr. Phys. 1984, 46, 173-191. [CrossRef]

10. McDade, I.C.; Llewellyn, E.J. The excitation of $\mathrm{O}\left({ }^{1} \mathrm{~S}\right)$ and $\mathrm{O}_{2}$ bands in the nightglow: a brief review and preview. Can. J. Phys. 1986, 12, 1626-1630. [CrossRef]

11. Clancy, R.T.; Rusch, D.W.; Thomas, R.J.; Allen, M.; Eckman, R.S. Model ozone photochemistry on the basic of solar mesosphere explorer mesospheric observations. J. Geophys. Res. 1987, 92, 3067-3080. [CrossRef]

12. Slanger, T.G.; Llewellyn, E.J.; McDade, I.C.; Witt, G. Comment on The $\mathrm{O}_{2}$ atmospheric dayglow in the thermosphere by M. R. Torr, B.Y. Welsh, and D. G. Torr. J. Geophys. Res. 1987, 92, 7753-7755. [CrossRef]

13. Evans, W.F.J.; McDade, I.C.; Yuen, J.; Llewellyn, E.J. A rocket measurement of the $\mathrm{O}_{2}$ Infrared Atmospheric (0-0) band emission in the dayglow and a determination of the mesospheric ozone and atomic oxygen densities. Can. J. Phys. 1988, 66, 941-946. [CrossRef]

14. Batista, P.P.; Takahashi, H.; Sahai, Y.; Llewellyn, E.J. Mesospheric ozone concentration at an equatorial location from the $1.27 \mu \mathrm{m} \mathrm{O}_{2}$ airglow emissions. J. Geophys. Res. 1996, 101, 7917-7921. [CrossRef]

15. McDade, I.C.; Murtagh, D.P.; Greer, R.G.H.; Dickinson, P.H.G.; Witt, G.; Stegman, J.; Llewellyn, E.J.; Thomas, L.; Jenkins, D.B. ETON 2: quenching parameters for the proposed precursor of $\mathrm{O}_{2}\left(\mathrm{~b}^{1} \Sigma_{\mathrm{g}}{ }^{+}\right)$and $\mathrm{O}\left({ }^{1} \mathrm{~S}\right)$ in the terrestrial nightglow. Planet. Space Sci. 1986, 34, 789-800. [CrossRef]

16. Murtagh, D.P.; McDade, I.C.; Greer, R.G.H.; Stegman, J.; Witt, G.; Llewellyn, E.J. ETON 4: an experimental investigation of the altitude dependence of the $\mathrm{O}_{2}(\mathrm{~A})$ vibrational populations in the nightglow. Planet. Space Sci. 1986, 34, 811-817. [CrossRef]

17. Greer, R.G.H.; Murtagh, D.P.; McDade, I.C.; Dickinson, P.H.G.; Thomas, L.; Jenkins, D.B.; Stegman, J.; Llewellyn, E.J.; Witt, G.; Mackinnon, D.J.; et al. ETON 1: A database pertinent to the study of energy transfer in the oxygen nightglow. Planet. Space Sci. 1986, 34, 771-788. [CrossRef]

18. Grygalashvyly, M.; Eberhart, M.; Hedin, J.; Strelnikov, B.; Lübken, F.-J.; Rapp, M.; Löhle, S.; Fasoulas, S.; Khaplanov, M.; Gumbel, J.; et al. Atmospheric band fitting coefficients derived from a self-consistent rocket-borne experiment. Atmos. Chem. Phys. 2019, 19, 1207-1220. [CrossRef]

19. Amaro-Rivera, Y.; Huang, T.-Y.; Urbina, J.; Vargas, F. Empirical values of branching ratios in the three-body recombination reaction for $\left.\mathrm{O}^{1} \mathrm{~S}\right)$ and $\mathrm{O}_{2}(0,0)$ airglow chemistry. Adv. Space Res. 2018, 62, 2679-2691. [CrossRef]

20. Lednyts'kyy, O.; von Savigny, C.; Sinnhuber, M.; Iwagami, N.; Mlynczak, M. Multiple Airglow Chemistry approach for atomic oxygen retrievals on the basis of in situ nightglow emissions. J. Atmos. Sol. Terr. 2019, 194, 105096. [CrossRef]

21. Mlynczak, M.G.; Solomon, S.C.; Zaras, D.S. An updated model for $\mathrm{O}_{2}\left(\mathrm{a}^{1} \Delta_{\mathrm{g}}\right)$ concentrations in the mesosphere and lower mesosphere and implications for remote sensing of ozone at $1.27 \mu \mathrm{m}$. J. Geophys. Res. 1993, 98, 18639-18648. [CrossRef]

22. Torr, M.T.; Torr, D.G. A Preliminary Spectroscopic Assessment of the Spacelab 1/Shuttle Optical Environment. J. Geophys. Res. 1985, 90, 1683-1690. [CrossRef]

23. Torr, M.R.; Owens, J.K.; Torr, D.G. Reply [to “Comment on 'The $\mathrm{O}_{2}$ Atmospheric dayglow in the thermosphere' by M. R. Torr, B.Y. Welsh, and D. G. Torr"]. J. Geophys. Res. 1987, 92, 7756-7760. [CrossRef]

24. Yee, J.-H.; DeMajistre, R.; Morgan, F. The $\mathrm{O}_{2}\left(\mathrm{~b}^{1} \Sigma_{\mathrm{g}}{ }^{+}\right)$dayglow emissions: application to middle and upper atmosphere remote sensing. Can. J. Phys. 2012, 90, 769-784. [CrossRef]

25. Slanger, T.G.; Copeland, R.A. Energetic Oxygen in the Upper Atmosphere and the Laboratory. Chem. Rev. 2003, 103, 4731-4766. [CrossRef] [PubMed]

26. Smith, A.K.; Harvey, V.L.; Mlynczak, M.G.; Funke, B.; Garcia-Comas, M.; Kaufmann, M.; Kyrölä, E.; López-Puertas, M.; McDade, I.; Randall, C.E.; et al. Satellite observations of ozone in the upper mesosphere. J. Geophys. Res. 2013, 118, 5803-5821. [CrossRef]

27. Mlynczak, M.G.; Morgan, F.; Yee, J.-H.; Espy, P.; Murtagh, D.; Marshall, B.T.; Schmidlin, F. Simultaneous measurements of the $\mathrm{O}_{2}\left(\mathrm{a}^{1} \Delta_{\mathrm{g}}\right)$ and $\mathrm{O}_{2}\left(\mathrm{~b}^{1} \Sigma_{\mathrm{g}}{ }^{+}\right)$airglows and ozone in the daytime mesosphere. Geophys. Res. Lett. 2001, 28, 999-1002. [CrossRef]

28. López-Puertas, M.; Taylor, F.W. Non-LTE Radiative Transfer in the Atmosphere; World Scientific Pub.: Singapore, 2001; Volume 3, 487p. 
29. Park, H.; Slanger, T.G. $\mathrm{O}_{2}(\mathrm{X}, \mathrm{v}=8-22) 300 \mathrm{~K}$ quenching rate coefficients for $\mathrm{O}_{2}$ and $\mathrm{N}_{2}$, and $\mathrm{O}_{2}(\mathrm{X})$ vibrational distribution from $248 \mathrm{~nm}$ O3 photodissociation. J. Chem. Phys. 1994, 100, 287-300. [CrossRef]

30. Yankovsky, V.A.; Manuilova, R.O. New self-consistent model of daytime emissions of $\mathrm{O}_{2}\left(\mathrm{a}^{1} \Delta_{\mathrm{g}}, \mathrm{v} \geq 0\right)$ and $\mathrm{O}_{2}\left(\mathrm{~b}^{1} \Sigma_{\mathrm{g}}{ }^{+}, \mathrm{v}=0,1,2\right)$ in the middle atmosphere. Retrieval of vertical ozone profile from the measured intensity profiles of these emissions. Atmos. Ocean. Opt. 2003, 16, 536-540.

31. Yankovsky, V.A.; Manuilova, R.O.; Kuleshova, V.A. Heating of the middle atmosphere as a result of quenching of the products of $\mathrm{O}_{2}$ and $\mathrm{O}_{3}$ photodissociation. SPIE Proc. Int. Soc. Opt. Eng. 2004, 5743, 34-40. [CrossRef]

32. Yankovsky, V.A.; Manuilova, R.O. Model of daytime emissions of electronically-vibrationally excited products of $\mathrm{O}_{3}$ and $\mathrm{O}_{2}$ photolysis: application to ozone retrieval. Ann. Geophys. 2006, 24, 2823-2839. [CrossRef]

33. Yankovsky, V.A.; Babaev, A.S. Photolysis of $\mathrm{O}_{3}$ at Hartley, Chappuis, Huggins, and Wulf Bands in the Middle Atmosphere: Vibrational Kinetics of Oxygen Molecules $\mathrm{O}_{2}\left(\mathrm{X}^{3} \Sigma^{-} \mathrm{g}, \mathrm{v} \leq 35\right)$. Atmos. Ocean. Opt. 2011, 24, 6-16. [CrossRef]

34. Yankovsky, V.A.; Manuilova, R.O.; Babaev, A.S.; Feofilov, A.G.; Kutepov, A.A. Model of electronic-vibrational kinetics of the $\mathrm{O}_{3}$ and $\mathrm{O}_{2}$ photolysis products in the middle atmosphere: applications to water vapor retrievals from SABER/TIMED $6.3 \mu \mathrm{m}$ radiance measurements. Int. J. Remote Sens. 2011, 32, 3065-3078. [CrossRef]

35. Yankovsky, V.A.; Manuilova, R.O. Possibility of simultaneous $\left[\mathrm{O}_{3}\right]$ and $\left[\mathrm{CO}_{2}\right]$ altitude distribution retrievals from the daytime emissions of electronically-vibrationally excited molecular oxygen in the mesosphere. J. Atmos. Sol. Terr. Phys. 2018, 179, 22-33. [CrossRef]

36. Bucholtz, A.; Skinner, W.R.; Abreu, V.J.; Hays, P.B. The dayglow of the O2 atmospheric band system. Planet. Space Sci. 1986, 34, 1031-1035. [CrossRef]

37. Mlynczak, M.G.; Marshall, B.T. A reexamination of the role of solar heating in the $\mathrm{O}_{2}$ atmospheric and infrared atmospheric bands. Geophys. Res. Lett. 1996, 23, 657-660. [CrossRef]

38. Witt, G.; Stegman, J.; Murtagh, D.P.; McDade, I.C.; Greer, R.G.H.; Dickinson, P.H.G.; Jenkins, D.B. Collisional energy transfer and the excitation of $\mathrm{O}_{2}\left(\mathrm{~b}^{1} \Sigma_{\mathrm{g}}{ }^{+}\right)$in the atmosphere. J. Photochem. 1984, 25, 365-378. [CrossRef]

39. Torr, M.T.; Torr, D.G. The role of metastable species in the thermosphere. Rev. Geophys. 1982, 20, 91-114. [CrossRef]

40. Svanberg, M.; Pettersson, J.B.C.; Murtagh, D. Ozone photodissociation in the Hartley band: A statistical description of the ground state decomposition channel $\mathrm{O}_{2}\left(\mathrm{X}^{3} \Sigma^{-} \mathrm{g}\right)+\mathrm{O}\left({ }^{3} \mathrm{P}\right)$. J. Chem. Phys. 1995, 102, 8887-8896. [CrossRef]

41. Sparks, R.K.; Carlson, L.R.; Snobatake, K.; Kowalczyk, M.L.; Lee, Y.T. Ozone photolysis: A determination of the electronic and vibrational state distributions of primary products. J. Chem. Phys. 1980, 72, 1401-1402. [CrossRef]

42. Valentini, J.J.; Gerrity, D.P.; Phillips, D.L.; Nieh, J.-C.; Tabor, K.D. CARS spectroscopy of $\mathrm{O}_{2}\left(\mathrm{a}^{1} \Delta_{\mathrm{g}}\right)$ from the Hartley band photodissociation of O3: Dynamics of the dissociation. J. Chem. Phys. 1987, 86, 6745-6756. [CrossRef]

43. Thelen, M.-A.; Gejo, T.; Harrison, J.A.; Huber, J.R. Photodissociation of ozone in the Hartley band: Fluctuation of the vibrational state distribution in the $\mathrm{O}_{2}\left(\mathrm{a}^{1} \Delta_{\mathrm{g}}\right)$ fragment. J. Chem. Phys. 1995, 103, 7946-7955. [CrossRef]

44. Dylewski, S.M.; Geiser, J.D.; Houston, P.L. The energy distribution, angular distribution, and alignment of the $\mathrm{O}\left({ }^{1} \mathrm{D}_{2}\right)$ fragment from the photodissociation of ozone between 235 and $305 \mathrm{~nm}$. J. Chem. Phys. 2001, 115, 7460-7473. [CrossRef]

45. Yankovsky, V.A.; Kuleshova, V.A. Ozone photodissociation at excitation within the Hartley absorption band. Analytical description of quantum yields $\mathrm{O}_{2}\left(\mathrm{a}^{1} \Delta_{\mathrm{g}}, \mathrm{v}=0-3\right)$ depending on the wavelength. Atmos. Ocean. Opt. 2006, 19, 514-518.

46. Yankovsky, V.A.; Kuleshova, V.A.; Manuilova, R.O.; Semenov, A.O. Retrieval of total ozone in the mesosphere with a new model of electronic-vibrational kinetics of $\mathrm{O}_{2}$ and $\mathrm{O}_{3}$ photolysis products. Izvestiya Atmos. Ocean. Phys. 2007, 43, 514-525. [CrossRef]

47. Martyshenko, K.V.; Yankovsky, V.A. IR Band of $\mathrm{O}_{2}$ at $1.27 \mu \mathrm{m}$ as the Tracer of $\mathrm{O}_{3}$ in the Mesosphere and Lower Thermosphere: Correction of the Method. Geomagn. Aeron. 2017, 57, 229-241. [CrossRef]

48. Klatt, M.; Smith, I.W.M.; Symonds, A.C.; Tuckett, R.P.; Ward, G.N. State-specific rate constants for the relaxation of $\mathrm{O}_{2}\left(X^{3} \Sigma^{-} \mathrm{g}, \mathrm{v}=8-11\right)$ in collisions with $\mathrm{O}_{2}, \mathrm{~N}_{2}, \mathrm{NO}_{2}, \mathrm{CO}_{2}, \mathrm{~N}_{2} \mathrm{O}$ and He. J. Chem. Soc. Faraday Trans. 1996, 92, 193-199. [CrossRef] 
49. Hernandez, R.; Toumi, R.; Clary, D.C. State-selected vibrational relaxation rates for highly vibrationally excited oxygen molecules. J. Chem. Phys. 1995, 102, 9544-9556. [CrossRef]

50. Watanabe, S.; Usuda, S.; Fujii, H.; Hatano, H.; Tokue, I.; Yamasaki, K. Vibrational relaxation of $\mathrm{O}_{2}\left(\mathrm{X}^{3} \Sigma^{-} \mathrm{g}\right.$, $\mathrm{v}=9-13$ ) by collisions with $\mathrm{O}_{2}$. Phys. Chem. Chem. Phys. 2007, 9, 4407-4413. [CrossRef]

51. Kalogerakis, K.S.; Copeland, R.A.; Slanger, T.G. Vibrational energy transfer in $\mathrm{O}_{2}\left(\mathrm{X}^{3} \Sigma^{-} \mathrm{g}, \mathrm{v}=2,3\right)+\mathrm{O}_{2}$ collisions at 330K. J. Chem. Phys. 2005, 123, 044309. [CrossRef]

52. Mack, J.A.; Mikulesky, F.; Wodtke, A.M. Resonant vibration-vibration energy transfer between highly vibrationally excited $\mathrm{O}_{2}(\mathrm{X}, \mathrm{v}=15-26)$ and $\mathrm{CO}_{2}, \mathrm{~N}_{2} \mathrm{O}, \mathrm{N}_{2}$, and $\mathrm{O}_{3}$. J. Chem. Phys. 1996, 105, 4105-4116. [CrossRef]

53. Rogaski, C.A.; Price, J.M.; Mack, J.A.; Wodtke, A.M. Laboratory evidence for a possible non-LTE mechanism of stratospheric ozone formation. Geophys. Res. Lett. 1993, 20, 2885-2888. [CrossRef]

54. Price, J.M.; Mack, J.A.; Rogaski, C.A.; Wodtke, A.M. Vibrational-state-specific self-relaxation rate constant. Measurements of highly vibrationally excited $\mathrm{O}_{2}(\mathrm{v}=19-28)$. Chem. Phys. 1993, 175, 83-98. [CrossRef]

55. Coletti, C.; Billing, G.D. Vibrational energy transfer in molecular oxygen collisions. Chem. Phys. Lett. 2002, 356, 14-22. [CrossRef]

56. Bloemink, H.I.; Copeland, R.A.; Slanger, T.G. Collisional removal of vibrationally excited $\mathrm{O}_{2}\left(\mathrm{~b}^{1} \Sigma_{\mathrm{g}}{ }^{+}\right)$by $\mathrm{O}_{2}$, $\mathrm{N}_{2}$, and $\mathrm{CO}_{2}$. J. Chem. Phys. 1998, 109, 4237-4245. [CrossRef]

57. Hwang, E.S.; Bergman, A.; Copeland, R.A.; Slanger, T.G. Temperature dependence of the collisional removal of $\mathrm{O}_{2}\left(\mathrm{~b}^{1} \Sigma_{\mathrm{g}}{ }^{+}, \mathrm{v}=1\right.$ and 2$)$ at 110-260 K, and atmospheric applications. J. Chem. Phys. 1999, 110, 18-24. [CrossRef]

58. Kalogerakis, K.S.; Copeland, R.A.; Slanger, T.G. Collisional removal of $\mathrm{O}_{2}\left(\mathrm{~b}^{1} \Sigma_{\mathrm{g}}{ }^{+}, \mathrm{v}=2,3\right)$. J. Chem. Phys. 2002, 116, 4877-4885. [CrossRef]

59. Pejakovic, D.A.; Campbell, Z.; Kalogerakis, K.S.; Copeland, R.A.; Slanger, T.G. Collisional relaxation of $\mathrm{O}_{2}\left(\mathrm{X}^{3} \Sigma^{-} \mathrm{g}, \mathrm{v}=1\right)$ and $\mathrm{O}_{2}\left(\mathrm{a}^{1} \Delta_{\mathrm{g}}, \mathrm{v}=1\right)$ by atmospherically relevant species. J. Chem. Phys. 2011, 135, 094309. [CrossRef]

60. Burkholder, J.B.; Abbatt, J.P.D.; Huie, R.E.; Kurylo, M.J.; Wilmouth, D.M.; Sander, S.P.; Barker, J.R.; Kolb, C.E.; Orkin, V.L.; Wine, P.H. Chemical Kinetics and Photochemical Data for Use in Atmospheric Studies: Evaluation Number 18; California Institute of Technology: Pasadena, CA, USA, 2015.

61. Yankovsky, V.A. Electron-vibrational relaxation of $\mathrm{O}_{2}\left(\mathrm{~b}^{1} \Sigma_{\mathrm{g}}{ }^{+}, \mathrm{v}=1,2\right)$ molecules in collision with ozone, oxygen molecules and atoms. Russ. J. Phys. Chem. 1991, 10, 291-306.

62. Esposito, F.; Armehise, I.; Capitta, G.; Capitelli, M. O-O $\mathrm{O}_{2}$ state-to-state vibrational-relaxation and dissociation rates based on quasiclassical calculations. Chem. Phys. 2008, 351, 91-98. [CrossRef]

63. Dayou, F.; Hernandez, M.I.; Campos-Martinez, J.; Hernandez-Lamoneda, R. Nonadiabatic couplings in the collisional removal of $\mathrm{O}_{2}\left(\mathrm{~b}^{1} \Sigma_{\mathrm{g}}{ }^{+}, \mathrm{v}\right)$ by $\mathrm{O}_{2}$. J. Chem. Phys. 2010, 132, 044313. [CrossRef] [PubMed]

64. Klingshirn, H.; Maier, M. Quenching of the ${ }^{1} \Sigma_{\mathrm{g}}{ }^{+}$state in liquid isotopes. J. Chem. Phys. 1985, 82, 714-719. [CrossRef]

65. Pejakovic, D.A.; Wouters, E.R.; Phillips, K.E.; Slanger, T.G.; Copeland, R.A.; Kalogerakis, K.S. Collisional removal of $\mathrm{O}_{2}\left(\mathrm{~b}^{1} \Sigma_{\mathrm{g}}{ }^{+}, \mathrm{v}=1\right)$ by $\mathrm{O}_{2}$ at thermospheric temperatures. J. Geophys. Res. 2005, 110A, A03308. [CrossRef]

66. Torbin, A.P.; Pershin, A.A.; Mebel, A.M.; Zagidullin, M.V.; Heaven, M.C.; Azyazov, V.N. Collisional relaxation of $\mathrm{O}_{2}\left(\mathrm{a}^{1} \Delta_{\mathrm{g}}, \mathrm{v}=1,2,3\right)$ by $\mathrm{CO}_{2}$. Chem. Phys. Lett. 2017, 691, 456-461. [CrossRef]

67. Wild, E.; Klingshirn, H.; Maier, M. Relaxation of the $\mathrm{a}^{1} \Delta_{\mathrm{g}}$ state on pure liquid oxygen and in liquid mixtures of $(16) \mathrm{O}_{2}$ and (18) $\mathrm{O}_{2}$. J. Photochem. 1984, 25, 134-143. [CrossRef]

68. Balakrishnan, N.; Dalgarno, A.; Billing, G.D. Multiquantum vibrational transitions in $\mathrm{O}_{2}(\mathrm{v} \geq 25)+\mathrm{O}_{2}(\mathrm{v}=0)$ collisions. Chem. Phys. Lett. 1998, 288, 657-662. [CrossRef]

69. Billing, G.D. VV and VT rates in $\mathrm{N}_{2}-\mathrm{O}_{2}$ collisions. Chem. Phys. 1994, 179, 463-467. [CrossRef]

70. Sharma, R.D.; Welsh, J.A. Vibrational energy transfer in $\mathrm{O}_{2}(\mathrm{v}=2-8)-\mathrm{O}_{2}(\mathrm{v}=0)$ collisions. J. Chem. Phys. 2009, 130, 194306. [CrossRef]

71. Yu, S.; Drouin, B.J.; Miller, C.E. High resolution spectral analysis of oxygen. IV. Energy levels, partition sums, band constants, RKR potentials, Franck-Condon factors involving the $\mathrm{X}^{3} \Sigma^{-} \mathrm{g}, \mathrm{a}^{1} \Delta_{\mathrm{g}}$ and $\mathrm{b}^{1} \Sigma_{\mathrm{g}}{ }^{+}$states. J. Chem. Phys. 2014, 141, 174302. [CrossRef] 
72. Nicholls, R.W. Franck-Condon Factors to High Vibrational Quantum Numbers V: $\mathrm{O}_{2}$ Band Systems. J. Res. Natl. Bur. Stand. Sect. Phys. Chem. 1965, 69A, 369-373. [CrossRef]

73. Krupenie, P.H. The spectrum of molecular oxygen. J. Phys. Chem. Ref. Data 1972, 1, 423-521. [CrossRef]

74. Minaev, B.F. Magnetic phosphorescence of molecular oxygen. A study of the $\mathrm{b}-\mathrm{X}$ transition probability using multiconfiguration response theory. Chem. Phys. 1996, 208, 299-311. [CrossRef]

75. Brown, L.R.; Plymate, C. Experimental line parameters of oxygen A band at 760 nm. J. Mol. Spectrosc. 2000, 199, 166-179. [CrossRef] [PubMed]

76. Gamache, R.R.; Goldman, A. Einstein A coefficient, integrated band intensity, and population factors: application to the $\mathrm{a}^{1} \Delta_{\mathrm{g}-} \mathrm{X}^{3} \Sigma^{-} \mathrm{g}(0,0) \mathrm{O}_{2}$ band. J. Quantative Spectrosc. Radiat. Transf. 2001, 69, 389-401. [CrossRef]

77. Goldman, A.; Stephen, T.V.; Rothman, L.S.; Giver, L.P.; Mandin, J.-Y.; Gamache, R.R.; Rinsland, C.P.; Murcray, F.J. The 1- $\mu \mathrm{m} \mathrm{CO} \mathrm{CO}_{2}$ bands and the $\mathrm{O}_{2}(0-1) \mathrm{X}^{3} \Sigma_{\mathrm{g}}{ }^{-}-\mathrm{a}^{1} \Delta_{\mathrm{g}}$ and (1-0) $\mathrm{X}^{3} \Sigma_{\mathrm{g}}{ }^{-} \mathrm{b}^{1} \Sigma_{\mathrm{g}}{ }^{+}$bands in the Earth atmosphere. J. Quantative Spectrosc. Radiat. Transf. 2003, 82, 197-205. [CrossRef]

78. Gordon, I.E.; Rothman, L.S.; Toon, G.C. Revision of spectral parameters for the B- and g-bands of oxygen and their validation against atmospheric spectra. J. Quantative Spectrosc. Radiat. Transf. 2011, 112, 2310-2322. [CrossRef]

79. Long, D.A.; Hodges, J.T. On spectroscopic models of the $\mathrm{O}_{2}$ A-band and their impact upon atmospheric retrievals. J. Geophys. Res. 2012, 117, D12309. [CrossRef]

80. Naus, H.; Ubachs, W. The $b^{1} \Sigma_{\mathrm{g}}{ }^{+}-\mathrm{X}^{3} \Sigma_{\mathrm{g}}{ }^{-}(3,0)$ band of $(16) \mathrm{O}_{2}$ and $(18) \mathrm{O}_{2}$. J. Mol. Spectrosc. 1999, 193, $442-445$. [CrossRef]

81. Rothman, L.S.; Rinsland, C.P.; Goldman, A.; Massie, S.T.; Edwards, D.P.; Flaud, J.M.; Schroeder, J. The HITRAN molecular spectroscopic database and hawks (HITRAN atmospheric workstation): 1996 Edition. J. Quantative Spectrosc. Radiat. Transf. 2010, 60, 665-710. [CrossRef]

82. Kuznetsova, L.A.; Kuzmenko, N.E.; Kuziakov, I.I.; Plastinin, I.A. Probabilities of Optical Transitions of Diatomic Molecules; Soviet Phys. Uspekhi. ed.; NAUKA: Moscow, Russia, 1980; 320p. (In Russian)

83. Kassi, S.; Romanini, D.; Campargue, A.; Bussery-Honvault, B. Very high sensitivity CW-cavity ring down spectroscopy: Application to the $\mathrm{a}^{1} \Delta_{\mathrm{g}}(0)-\mathrm{X}^{3} \Sigma^{-} \mathrm{g}(1) \mathrm{O}_{2}$ band near $1.58 \mu \mathrm{m}$. Chem. Phys. Lett. 2005, 409, 281-287. [CrossRef]

84. Gamache, R.R.; Goldman, A.; Rothman, L.S. Improved spectral parameters for the three most abundant isotopomers of the oxygen molecule. J. Quantative Spectrosc. Radiat. Transf. 1998, 59, 495-509. [CrossRef]

85. Christensen, A.B.; Yee, J.-H.; Bishop, R.L.; Budzien, S.A.; Hecht, J.H.; Sivjee, G.; Stephan, A.W. Observations of molecular oxygen Atmospheric band emission in the thermosphere using the near infrared spectrometer on the ISS/RAIDS experiment. J. Geophys. Res. 2012, 117, A04315. [CrossRef]

86. Slanger, T.G.; Pejakovic, D.A.; Kostko, O.; Matsiev, D.; Kalogerakis, K.S. Atmospheric dayglow diagnostics involving the $\mathrm{O}_{2}(\mathrm{~b}-\mathrm{X})$ Atmospheric band emission: Global Oxygen and Temperature (GOAT) mapping. J. Geophys. Res. Space Phys. 2017, 122, 3640-3649. [CrossRef]

87. Klotz, R.; Marian, C.M.; Peyrimhoff, S.D.; Hess, B.A.; Buenker, R.J. Calculation of spin-forbidden radiative transitions using correlated wavefunctions: lifetimes of $\mathrm{b}$, a states in $\mathrm{O}_{2}, \mathrm{~S}_{2}$ and SO. Chem. Phys. 1984, 89, 223-236. [CrossRef]

88. Slanger, T.G.; Black, G. $\mathrm{O}\left({ }^{1} \mathrm{~S}\right)$ in the lower thermosphere-Chapman vs. Barth. Planet. Space Sci. 1977, 25, 79-88. [CrossRef]

89. Wu, K.; Fu, D.; Feng, Y.; Li, J.; Hao, X.; Li, F. Simulation and application of the emission line $\mathrm{O}_{19} \mathrm{P}_{18}$ of $\mathrm{O}_{2}\left(\mathrm{a}^{1} \Delta_{\mathrm{g}}\right)$ dayglow near $1.27 \mu \mathrm{m}$ for wind observations from limb-viewing satellites. Opt. Express 2018, 26, 16984-16999. [CrossRef]

90. Atkinson, R.; Baulch, D.L.; Cox, R.A.; Crowley, J.N.; Hampson, R.F.; Hynes, R.G.; Jenkin, M.E.; Rossi, M.J.; Troe, J. Evaluated kinetic and photochemical data for atmospheric chemistry: Volume I-gas phase reactions of $\mathrm{O}_{\mathrm{x}}, \mathrm{HO}_{\mathrm{x}}, \mathrm{NO}_{\mathrm{x}}$ and $\mathrm{SO}_{\mathrm{x}}$ species. Atmos. Chem. Phys. 2004, 4, 1461-1738. [CrossRef]

91. Balakrishnan, N.; Billing, G.D. Quantum-classical reaction path study of the reaction $\mathrm{O}\left({ }^{3} \mathrm{P}\right)+\mathrm{O}_{3}\left({ }^{1} \mathrm{~A}_{1}\right) \rightarrow 2$ $\mathrm{O}_{2}\left(\mathrm{X}^{3} \Sigma^{-}\right.$g). J. Chem. Phys. 1996, 104, 9482-9494. [CrossRef]

92. SABER-Sounding of the Atmosphere Using Broadband Emission Radiometry. Available online: http: //saber.gats-inc.com/data.php (accessed on 19 January 2020). 
93. SORCE. Available online: http://science.nasa.gov/missions/sorce/ (accessed on 19 January 2020).

94. He, W.; Wu, K.; Feng, Y.; Fu, D.; Chen, Z.; Li, F. Radiative Transfer Characteristics of the O2 Infrared Atmospheric Band in Limb-Viewing Geometry. Remote Sens. 2019, 11, 2702. [CrossRef]

(C) 2020 by the authors. Licensee MDPI, Basel, Switzerland. This article is an open access article distributed under the terms and conditions of the Creative Commons Attribution (CC BY) license (http://creativecommons.org/licenses/by/4.0/). 